RENATA FARINELLI DE SIQUEIRA

\title{
USO DA CUTINA NA ESTIMATIVA DA DIGESTIBILIDADE APARENTE DE DIETAS PARA EQÜINOS
}




\section{RENATA FARINELLI DE SIQUEIRA}

Uso da cutina na estimativa da digestibilidade aparente de dietas para eqüinos

Dissertação apresentada ao Programa de PósGraduação em Nutrição Animal da Faculdade de Medicina Veterinária e Zootecnia para obtenção do título de Mestre em Medicina Veterinária

\section{Departamento:}

Nutrição e Produção Animal

Área de concentração:

Nutrição Animal

Orientador:

Prof. Dr. Alexandre Augusto de Oliveira Gobesso

Pirassununga

2008 
Autorizo a reprodução parcial ou total desta obra, para fins acadêmicos, desde que citada a fonte.

\section{DADOS INTERNACIONAIS DE CATALOGAÇÃO-NA-PUBLICAÇÃO}

(Biblioteca Virginie Buff D’Ápice da Faculdade de Medicina Veterinária e Zootecnia da Universidade de São Paulo)

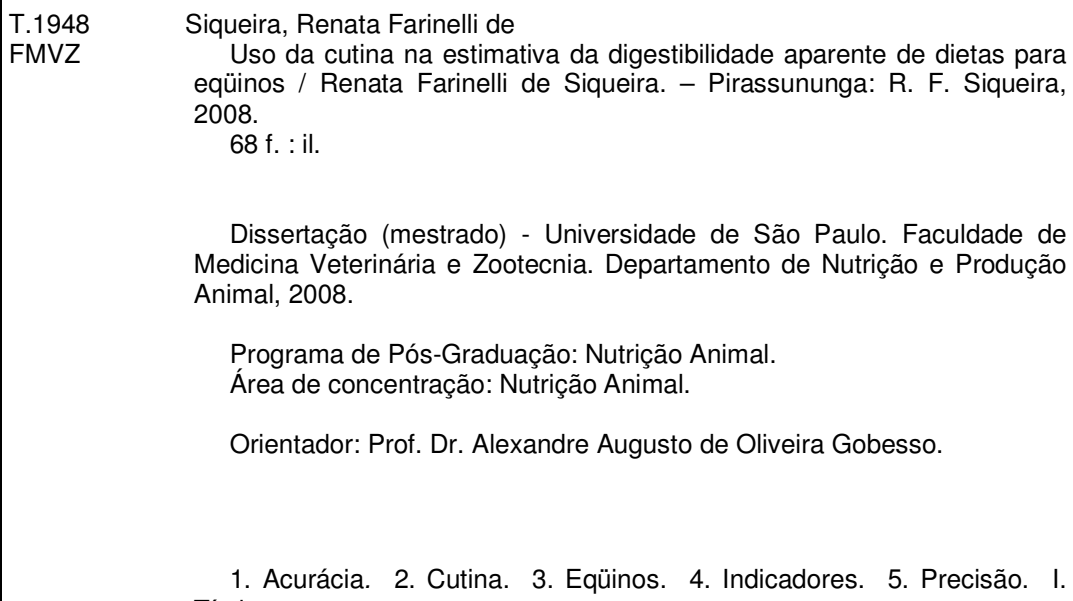




\title{
BIOÉTICA
}

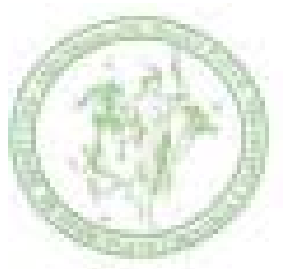

\author{
UNTVESIDADE DE SĀO PAULO \\ Faculdade de Medicina Veterinaria c Zootecnia \\ Comissto Biotica \\ CERTIFICADO
}

Certifiamos que of Profeto intitulado "Uso da aitina e oulinos indicadores na estimativa da digestibilidade aparente de dikrentes dietas em equinos:" protocclade sob of $\pi 1249 / 200 \%$, utilizando 04 (quatro) oquinos, sob a responabilidade do Prot. Lr. Alexandre Augusto de Oiveina Gobess, ets de acordo com os principlos tticos de esperimentaça animal da Contsolio de Biobtica da Faculdade de Medicina Veterinatria e Zootennia da Univeraidade de Sino Paulo e foi aprovado "ac referendum".

We cetity that the Reseanh "Use of cutin anf ather markers in estimated apparent digestibility in different oquine diets". protocol number 1249/200\%, utilizing o4 (four) equinus, under the responsibility Prof. Dr. Alekandre Augusto de Oliveira Goberso, apres with Fthical Principles in Animal Remeard adopted by Biosthic Commission of the School of Veterinary Medicine and Anfmal Science of University of Swo Paulo and was approned "tod referendum", neeting

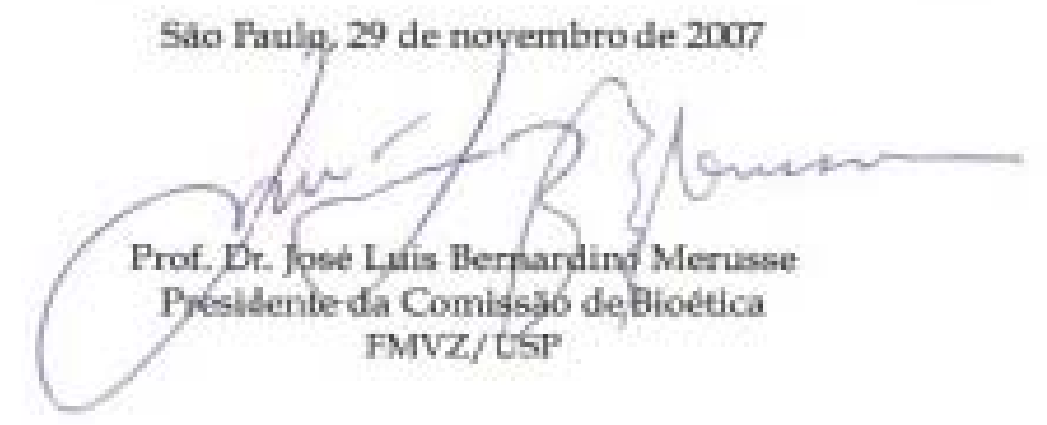




\section{FOLHA DE AVALIAÇÃO}

Nome: SIQUEIRA, Renata Farinelli

Título: Uso da cutina na estimativa da digestibilidade aparente de dietas para eqüinos

Dissertação apresentada ao Programa de Pós-Graduação em Nutrição Animal da Faculdade de Medicina Veterinária e Zootecnia para obtenção do título de Mestre em Medicina Veterinária

Data:

Banca Examinadora:

Prof. Dr.

Assinatura:

Prof. Dr.

Assinatura:

Prof. Dr.

Assinatura:
Instituição:

Julgamento:

Instituição:

Julgamento:

Instituição:

Julgamento: 
Á minha mãe.......

Quem me criou sozinha, foi pai, mãe ("supermãe"),

Me ensinou a sonhar e a lutar pelos meus sonhos....

Está sempre ao meu lado, nos momentos alegres e tristes.

Ao Rodrigo, por estar do meu lado o tempo todo...

Pelo amor, pela amizade, carinho e muita paciência!!

Pela grande ajuda!!

Dedico 


\section{AGRADECIMENTOS}

A Deus, portercolocadoemmeucaminhopessoas que me ajudaram, de várias formas, sempre que precisei! Em nenhum momento da minha vida, estive sozinha!

A todos os queridos professores e orientadores de estágio, que contribuíram indiretamente para que eu chegasse até aqui, me ensinando, me apoiando e guiando meus passos, desde a graduação.

Ao meu namorado Rodrigo, pela amizade, pelo companheirismo, pelo carinho e pela paciência! Por ter participado intensamente deste trabalho, deixando, muitas vezes, de lado as suas coisas para me socorrer.

Ao Prof.AlexandreGobesso, pelaorientaçãoeporterabertoasportasda pós graduação.

AoProf.RomualdoFukushimaportercedidodadosqueforam utilizados neste trabalho e pela disposição em ajudar.

Ao Prof. Paulo Mazza pelaorientaçãoestatística , pelapaciênciaepela disponibilidade.

A todososmeusamigos peloapoio,torcidae, principalmente, porcompreendere perdoar a minha ausência. 


\section{RESUMO}

SIQUEIRA,RF.Usoda cutina na estimativa da digestibilidade aparente de dietas para eqüinos. [Useofcutinfordeterminingapparentdigestibility of diets in horses] 2008. 68 f. Dissertação (Mestrado em Medicina Veterinária) - Faculdade de Medicina Veterinária e Zootecnia, Universidade de São Paulo, São Paulo, 2008.

Com o objetivo de comparar as estimativas dos coeficientes de digestibilidade dos nutrientes de dietas paraeqüinoscompostas poralfafa em cubos, alfafa em cubos com óleo de soja, alfafa em ramasealfafaemramascomóleo desoja, através do método de coleta total de fezes com o uso dos indicadores cutina, óxido crômico e lignina em detergente ácido, foram utilizados 4 eqüinos machos, sem raça definida, com idade aproximada de 10 meses e peso médio de $197 \mathrm{Kg}(170 \mathrm{kga} 216 \mathrm{~kg})$ Oexperimento teve duração de 11 dias, sendo 8 de adaptação e 3decoleta.Odelineamento experimental utilizado foi o quadrado latino 4 X4. A ponderaçãodoscoeficientesdedigestibilidade da matéria orgânica (CDMO) pelos indicadores foi efetuada através de um modelo o qual consideravaadiferença entre CDMO peloindicadorepelacoletatotaldefezes, chamado de viés. Paraaavaliaçãodosindicadoresutilizados, forammedidasaacurácia, a precisão e a robustez. A acurácia e a precisãoforamdeterminadaspelacomparação dos dados preditos com os observados. Arobustezfoi determinada pela comparação dos valores preditosmenososobservados(vieses)comoutrosfatoresestudados(EE na dieta,ED na dieta e peso vivo). Neste estudo, a cutina não se mostrou adequada como indicador interno, pois superestimou a digestibilidade aparente da matéria orgânica( DAMO), apresentou a menor acurácia e menor precisão. O óxido crômico apresentou baixa recuperaçãofecalesubestimouaDAMO, emboratenhasido o mais preciso. A LDA foi o indicador que obteve a melhor recuperação fecal e foi o mais acurado, portanto, 0 indicador mais adequado, todos em relação à coleta total de fezes na estimativa da digestibilidade aparente da matéria orgânica de dietas para eqüinos.

Palavras-chave: Acurácia. Cutina. Eqüinos. Indicadores. Precisão. 


\begin{abstract}
SIQUEIRA, R. F. Use of cutin for determining apparent digestibility of diets in horses. [Usodacutinanaestimativadadigestibilidadeaparente de dietas para eqüinos]. 2008.68f.Dissertação (Mestrado em Medicina Veterinária) - Faculdade de Medicina Veterinária e Zootecnia, Universidade de São Paulo, São Paulo, 2008.
\end{abstract}

Thisresearchaimedto compare organic matter digestibility coefficient (OMDC) of diets composed ofalfalfacubes, alfalfacubeswith soybean oil, alfalfa hay and alfalfa hay with soybeanoilbytotalfecescollectionanduse the internal markers cutin and acid detergent lignin ( $A D L)$ and the external marker chromic oxide. Four male weanling horses (approximately 10-monthsold, 197.25kgBWaverage) were used in a $4 \times 4$ Latin Square design. Evaluation ofOMDCestimated bymarkerswasperformed bya model considering the bias, i.e., the difference between OMDC estimated by marker and by total feces collection. Itwasevaluatedaccuracy, precision and robustness of those three markers. The cutinoverestimatedtheOMDCandshowedtobe the less accurate and precise. The chromicoxide underestimatedthe OMDC and its recovery was low, but it was the most precise. The ADL recovery did not differ from $100 \%$ and it was the most accurate, therefore the most appropriated marker for this kind of diet.

Key words: Accuracy. Cutin. Digestibility. Horses. Markers. Precision. 


\section{LISTA DE TABELAS}

Tabela 1 - Composição química dos ingredientes com base na matéria seca..

Tabela 2 - Composição de ingredientes das dietas experimentais com base na matéria original, em função dos tratamentos

Tabela 3 - Composição química das dietas experimentais com base na matéria seca.

Tabela 4 - Consumo de matéria seca diário, concentração dos indicadores na dieta e ingestão diária dos indicadores em função das dietas utilizadas.

Tabela 5 - Recuperação fecal dos indicadores cutina, lignina em detergente ácido (LDA) e óxido crômico para estimativa da digestibilidade aparente da matéria orgânica (DAMO) em eqüinos

Tabela 6 - Médias dos quadrados mínimos da digestibilidade aparente da matéria orgânica (\%) em função do método de determinação da produção fecal e das dietas utilizadas no experimento.

Tabela 7 - Parâmetros de avaliação da acurácia e precisão da estimativa da digestibilidade aparente da matéria orgânica (DAMO) em eqüinos pelos indicadores cutina, lignina em detergente ácido (LDA) e óxido crômico

Tabela 8 - Avaliação da robustez (coeficiente angular, $\mathrm{R}^{2}$ e probabilidade) das estimativas da digestibilidade aparente da matéria orgânica (DAMO) em eqüinos, através dos indicadores cutina, lignina em detergente ácido (LDA) e óxido crômico. 


\section{LISTA DE FIGURAS}

Figura 1 - Regressão entre vieses e digestibilidade aparente da matéria orgânica observada (DAMO) em eqüinos para o indicador cutina.

Figura 2 - Regressão entre vieses e digestibilidade aparente da matéria orgânica observada (DAMO) em eqüinos para o indicador lignina em detergente ácido (LDA)

Figura 3 - Regressão entre vieses e digestibilidade aparente da matéria orgânica observada (DAMO) em eqüinos para o indicador óxido crômico .... 44

Figura 4 - Regressão linear entre os vieses da predição da digestibilidade aparente da matéria orgânica em eqüinos pelo indicador cutina e teores de extrato etéreo (EE) na dieta 50

Figura 5 - Regressão linear entre os vieses da predição da digestibilidade aparente da matéria orgânica em eqüinos pelo indicador lignina em detergente ácido (LDA) e teores de extrato etéreo (EE) na dieta.

Figura 6 - Regressão linear entre os vieses da predição da digestibilidade aparente da matéria orgânica em eqüinos pelo indicador óxido crômico e teores de extrato etéreo (EE) na dieta................................................ 52

Figura 7 - Regressão linear entre os vieses da predição da digestibilidade aparente da matéria orgânica em eqüinos pelo indicador cutina e teores de energia digestível (ED) na dieta

Figura 8 - Regressão linear entre os vieses da predição da digestibilidade aparente da matéria orgânica em eqüinos pelo indicador lignina em detergente ácido (LDA) e teores de energia digestível (ED) na dieta. 54

Figura 9 - Regressão linear entre os vieses da predição da digestibilidade aparente a matéria orgânica em eqüinos pelo indicador óxido crômico e teores e energia digestível (ED) na dieta

Figura 10 - Regressão linear entre os vieses da predição da digestibilidade aparente da matéria orgânica em eqüinos pelo indicador cutina e peso vivo $(\mathrm{PV})$

Figura 11 - Regressão linear entre os vieses da predição da digestibilidade aparente da matéria orgânica em eqüinos pelo indicador lignina em detergente ácido (LDA) e peso vivo (PV).

Figura 12 - Regressão linear entre os vieses da predição da digestibilidade aparente da matéria orgânica em eqüinos pelo indicador óxido crômico e peso vivo (PV). 


\section{LISTA DE ABREVIATURAS}

CD - Coeficiente de digestibilidade

CDFDA - Coeficiente de digestibilidade de FDA

CDFDN - Coeficiente de digestibilidade de FDN

CDMO - Coeficiente de digestibilidade da matéria orgânica

CDMS - coeficiente de digestibilidade da matéria seca

CELi - Celulose indigestível

CIA - Cinzas insolúveis em ácido

CIDA - Cinzas insolúveis em detergente ácido

$\mathrm{cm}$ - centímetro

CMO - Consumo de matéria orgânica

CMS - Consumo de matéria seca

$\mathrm{Cr}$ - Cromo

$\mathrm{Cr}_{2} \mathrm{O}_{3}$ - Óxido crômico

CT - Coleta total de fezes

CV - coeficiente de variação

DAMO - Digestibilidade aparente da matéria orgânica

EAA - Espectrofotometria de absorção atômica

EB - Energia bruta

ED - Energia digestível

EE - Extrato etéreo

ENN - Extrativo não nitrogenado

FB - Fibra bruta

FDA - Fibra em detergente ácido

FDAi - Fibra em detergente ácido indigerível

FDN - Fibra em detergente neutro

g - Gramas

$\mathrm{Kg}$ - Quilogramas

LDA - Lignina em detergente ácido

$\mathrm{m}$ - Metros

$\mathrm{MM}$ - Matéria mineral 
MO - Matéria orgânica

MS - Matéria seca

n - número amostral

$\mathrm{NaClO}_{2}-$ Clorito de sódio

NDT - Nitrogênio digestivel total

NRC - NACIONAL RESEARCH COUNCIL

ns - não significativo

PB - Proteína bruta

$\mathrm{Pr}$ - Probabilidade

PV - Peso vivo

RQMEP - raiz quadrada média do erro de predição 


\section{LISTA DE SÍMBOLOS}

\% Porcentagem

${ }^{\circ} \mathrm{C} \quad$ Graus Celsius

$\mathrm{mm}^{2} \quad$ Milímetro quadrado

$+\quad$ Mais

- $\quad$ Menos

$>\quad$ Maior

$<\quad$ Menor

$\sqrt{ } \quad$ Raiz quadrada

x Vezes 


\section{SUMÁRIO}

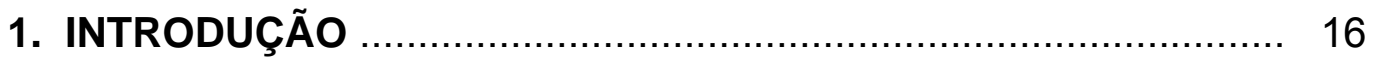

2. REVISÃO DE LITERATURA …............................................ 17

2.1. CONSIDERAÇÕES SOBRE ANATOMIA ............................. 17

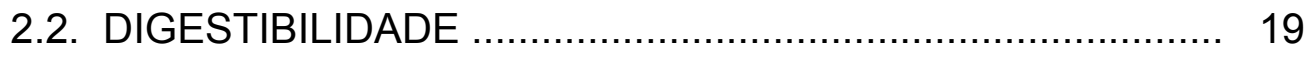

2.3. MÉTODOS PARA A ESTIMATIVA DOS COEFICIENTES DE DIGESTIBILIDADE ..................................................... 20

2.4. ÓXIDO CRÔMICO …….................................................... 22

2.5. INDICADORES INTERNOS ………………........................ 23

3. OBJETIVO

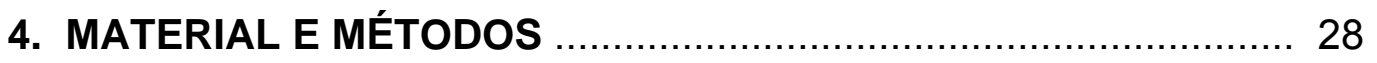

4.1. DETERMINACÃO DA DAMO PELA TÉCNICA DE COLETA TOTAL

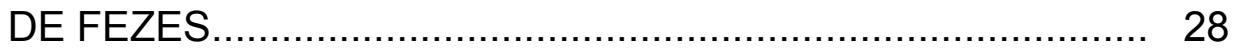

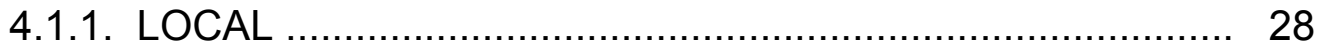

4.1.2. ANIMAIS E INSTALAÇÕES.......................................... 28

4.1.3. DELINEAMENTOEXPERIMENTAL E ALIMENTACÃO......... 29

4.1.4. COLETA TOTAL DE FEZES, AMOSTRAGEM E ANÁLISES

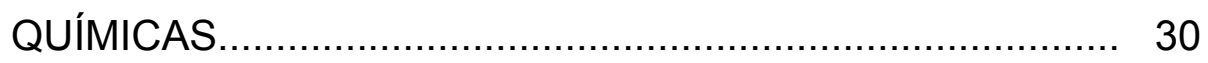

4.2.EMPREGO DOS INDICADORES PARA O CÁLCULO DA DAMO PREDITA ............................................................... 32

4.2.1. EQUAÇÕES................................................................ 33

4.3. AVALIACÃO DOS INDICADORES....................................... 34

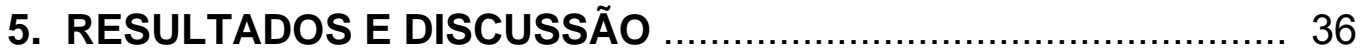

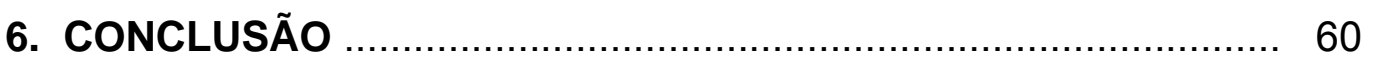

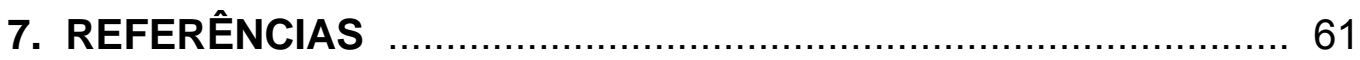




\section{INTRODUÇÃO}

A determinação da digestibilidade é conhecidamente o passo inicial para a avaliação da importância nutritiva de um alimento. $O$ conhecimento das peculiaridades fisiológicas inerentes à espécie eqüina conjuntamente com a avaliação da digestibilidade dos alimentos são fundamentais para a evolução das pesquisas visando à criação de modelos nutricionais consistentes para essa espécie animal.

Ensaios de digestibilidade com eqüinos, através da coleta total de fezes, auxiliam a determinação da digestibilidade aparente total, ou seja, dão uma idéia de como se comportam os nutrientes ao longo de todo o trato gastrintestinal.

Esta técnica possui o inconveniente de restringir o número de animais experimentais à disponibilidade de infra-estrutura adequada, além de exigir mão-deobra qualificada. Outro fator negativo consiste em que durante o período experimental os animais ficam confinados em condições desfavoráveis a manutenção da espécie eqüina, levando a irregularidades fisiológicas com influência negativa sobre o processo digestivo.

A digestibilidade dos nutrientes em dietas para eqüinos pode também ser estimada de forma indireta, por meio de indicadores internos e externos. $\mathrm{O}$ indicador externo de uso mais freqüente é o óxido crômico e, como método indireto, baseia-se na recuperação total nas fezes do indicador ingerido. Entre os indicadores internos têm sido estudados alguns componentes da fração fibrosa dos alimentos, como a fibra em detergente neutro (FDN) e a fibra em detergente ácido (FDA) indigestíveis, lignina em detergente ácido (LDA), cinza insolúvel em ácido (CIA), cinza insolúvel em detergente ácido (CIDA) e a cutina. Alterações na excreção dos indicadores ou na análise dos mesmos nas fezes ou nas dietas podem comprometer sua utilização nos ensaios de digestão.

$\mathrm{O}$ indicador ideal para determinar a digestibilidade e a produção fecal total deve possuir algumas propriedades fundamentais como não ser digerido totalmente, ser farmacologicamente inativo no trato digestivo, possuir taxa de passagem uniforme, poder ser determinado quimicamente e, de preferência, ser uma substância naturalmente presente nos alimentos. 
Silva et al. (2006) utilizaram a cutina como indicador interno na estimativa da digestibilidade da matéria seca em novilhos e relataram que, apesar de ter subestimado a digestibilidade, este indicador apresenta potencial, mas recomenda a realização de novos experimentos visando estudar sua correlação com a coleta total de fezes e outros indicadores.

\section{REVISÃO DE LITERATURA}

Nesta seção serão abordados alguns temas como anatomia, digestibilidade, métodos para a estimativa dos coeficientes de digestibilidade e utilização dos indicadores internos e do óxido crômico.

\subsection{CONSIDERAÇÕES SOBRE ANATOMIA}

Os eqüinos são classificados, segundo a anatomia do seu trato digestivo, como sendo herbívoros não ruminantes, mais especificamente podem ser considerados como herbívoros com ceco funcional, apresentando algumas vantagens sobre os estritamente não ruminantes e os ruminantes. Tais características anatômicas e fisiológicas permitem que os eqüinos possam absorver os carboidratos contidos nos concentrados energéticos antes do ataque da microflora intestinal.

O processo digestivo começa com a apreensão dos alimentos, pelos lábios e a língua sendo também utilizados os dentes incisivos na ingestão de substâncias mais firmes como tubérculos e ramos. Na boca, eqüinos com dentição funcional e intacta, esmagam e moem os alimentos, liberando proteínas e carboidratos que podem ser prontamente digeridos no estômago e intestino delgado.

Os cavalos pastam com os dentes e não com a língua, como os ruminantes. Isto implica numa maior ingestão das pastagens e também das partes mais fibrosas dos alimentos. O fornecimento de alimentação suficientemente fibrosa é necessário para induzir a atividade mastigatória, levando a uma produção adequada de saliva e conseqüente mistura com o alimento. 
A saliva é secretada na boca, dependendo da quantidade de alimento que é ingerido. Não contém enzimas digestivas como as alfa-amilases, portanto, os carboidratos não são digeridos no estômago, porém, a saliva possui outras importantes funções, como o tamponamento da acidez estomacal pela grande quantidade de bicarbonato e a prevenção de obstrução esofagiana pela quantidade de muco que lubrifica o bolo alimentar.

O contínuo tamponamento do estômago proximal é necessário para que ocorra a fermentação microbiana e produção de lactato pela fermentação de alguns carboidratos. Este lactato é reabsorvido no intestino delgado ou convertido em ácidos graxos voláteis no intestino grosso (JANSSENS, 2002).

O estômago dos eqüinos tem capacidade de 15 a 20 litros, ajustado para uma recepção contínua de pequenas quantidades de alimento. É preenchido em camadas na região do saco cego aglandular e na região glandular fúndica, sendo posteriormente conduzido ao terço final onde será liquefeito. Os processos digestivos neste local são concretizados por uma atividade simultânea das enzimas alimentares, microorganismos e do suco gástrico (MEYER, 1995).

Frape (1992) cita que o tempo de permanência dos alimentos no estômago varia de 2 a 3 horas, porém Konhke (1992) considera um tempo mínimo de retenção de 20 minutos, limitando assim a ação de secreções gástricas. Essa velocidade de trânsito, associada ao $\mathrm{pH}$ ácido, restringe a ação da população microbiana na fermentação de açúcares e amido.

A mucosa duodenal possui glândulas que secretam suco entérico e grande quantidade de muco, suas inúmeras vilosidades revestidas de células epiteliais cilíndricas com microvilosidades aumentam a superfície de absorção dos alimentos (MEYER 1995).

Wolter (1975) cita que a parede do intestino delgado é muito musculosa, rígida e ricamente enervada, propiciando a geração de fortes ondas de contração, facilitando assim a progressão da ingesta associada a sua grande fluidez resultante do sinergismo das secreções salivar, gástrica, pancreática, biliar e entérica. A digestão, no intestino delgado dos eqüinos é intensa e predominantemente enzimática. Os principais nutrientes digeridos são proteína bruta (PB), extrato etéreo (EE), amido e carboidratos, semelhante à digestão dos monogástricos (WOLTER, 1975; HINTZ 1979; FRAPE 1992; KOHNKE 1992).

O intestino grosso do cavalo compreende seções volumosas, bem articuladas 
e compartimentalizadas. A atividade do ceco e do cólon depende principalmente do tipo e da quantidade de substâncias nutritivas provenientes do intestino delgado, da velocidade de trânsito do alimento ingerido e da capacidade de tamponamento no lúmen. O número de microorganismos no conteúdo do intestino grosso de eqüinos é semelhante ao encontrado no rúmen e retículo dos ruminantes. (MEYER, 1995).

O volume do ceco e do cólon é de aproximadamente 120 litros e juntos representam a maior parte do sistema digestivo do eqüino. O bicarbonato proveniente do pâncreas eleva o pH intestinal a um nível que permite a fermentação microbiana. Exatamente como ocorre no rúmen, as fontes de nitrogênio são parcialmente convertidas em proteínas microbianas de alta qualidade. Os ácidos graxos voláteis resultantes da fermentação das fibras contribuem consistentemente para a provisão energética dos cavalos. A contribuição dos protozoários no intestino grosso é limitada. (JENSSENS, 2002)

\subsection{DIGESTIBILIDADE}

A estimativa da digestibilidade é o primeiro passo para a avaliação da energia na alimentação. Nos eqüinos, assim como em todas as espécies cuja fermentação microbiana desempenha papel fundamental na digestão, as interações entre os ingredientes são mais importantes do que para os outros animais. (ZEYNER, 2002)

A digestibilidade dos nutrientes no alimento é comumente expressa como porcentagem do nutriente que desaparece no balanço entre a ingestão e a excreção.

O sistema de avaliação de alimentos normalmente utilizado para eqüinos tem sido o mesmo usado para ruminantes, embora diferenças importantes no processo de digestão devam ser observadas, por causa da diferença na compartimentalização do trato digestivo, o que se traduz em diferentes coeficientes de digestibilidade. (OLIVEIRA et al., 2003)

Para Fuller (1991) os coeficientes de digestibilidade aparentes têm sido aceitos por oferecerem valores próximos dos reais como medidas da utilização de cada componente da dieta na alimentação animal. Segundo Nyberg (1993) proteínas e lipídios sofrem ação do processo digestivo sendo em parte absorvidos e utilizados pelo organismo. Além da fração não digerida destes nutrientes e eliminada pelas 
fezes, existem compostos formados pela ação da extensa flora gastrintestinal, que são considerados como parte utilizada.

Oliveira (1995) observou aumento na digestibilidade dos constituintes de parede celular em função da redução no teor de FDN das dietas. O menor consumo deste nutriente pode reduzir a taxa de passagem, elevando, conseqüentemente, o tempo de retenção da digesta no ceco e cólon, favorecendo a fermentação da fibra.

Martin-Rosset et al. (1990) estudaram a influência do nível de consumo na digestibilidade dos nutrientes de uma ração contento $85 \%$ de feno e $15 \%$ de concentrado em cavalos adultos de raças leves, verificando que o consumo não afeta a digestibilidade das forragens para eqüinos. Segundo os autores, a alimentação de mantença e $60 \%$ acima da mantença não afetaram os coeficientes da MS, MO, PB, FB e EB.

Muares possuem maior capacidade de digestão de FDA e FDN do que cavalos e pôneis, provavelmente pelo fato dos muares serem capazes de reterem mais partículas alimentares por longo tempo no aparelho digestivo em comparação a outros animais (CUDDERFORD et al., 1995).

\subsection{MÉTODOS PARA A ESTIMATIVA DOS COEFICIENTES DE DIGESTIBILIDADE}

A estimativa de valores de digestibilidade é reconhecidamente um dos primeiros parâmetros do valor nutritivo do alimento, contudo experimentos para determinação de digestibilidade através da coleta total de fezes são onerosos e necessitam de adaptação dos animais às gaiolas metabólicas. $\mathrm{O}$ uso de indicadores naturais constituintes da dieta representa um método alternativo da coleta total e aos indicadores externos como o óxido crômico $\left(\mathrm{Cr}_{2} \mathrm{O}_{3}\right)$.

Os métodos mais empregados para determinação de digestibilidade dos nutrientes em eqüinos são a coleta total, e os indicadores externos e internos.

De acordo com Olsson e Ruudvere (1955), uma série de fatores afeta a digestão nos eqüinos, como a individualidade do animal, tipo de trabalho, composição química do alimento, granulometria e conteúdo de água, velocidade de 
trânsito no trato digestivo e quantidade de fibra presente na ração (ARAÚJO et al., 2003).

O método de coleta total, também chamado de convencional ou padrão, consiste no controle do alimento ingerido e na coleta total das excreções dos animais, sendo os coeficientes de digestibilidade aparente calculados a partir da análise química de cada fração (LLOYD, 1978). Sankhyan et al., (1999) descreveram a técnica como sendo a mais acurada para determinação de digestibilidade aparente em animais.

Dentre os métodos de coleta total mais utilizados na determinação da digestibilidade dos nutrientes em eqüinos, destacam-se as baias com pisos e paredes impermeabilizadas, as bolsas coletoras e as gaiolas metabólicas (ARAÚJO, 1999).

Vander Noot et al. (1965) desenvolveram bolsas coletoras para contornar as dificuldades próprias a coleta quantitativa das fezes. De acordo com Parkins et al. (1982), o emprego de bolsas coletoras implica na utilização de arreios apropriados, fazendo com que alguns animais não se adaptem perfeitamente ao sistema apresentando inconstância fisiológica.

As gaiolas metabólicas começaram a serem utilizadas com a finalidade de diminuir as dificuldades encontradas com a utilização das bolsas coletoras (STILLIONS, 1968). Knapka et al. (1967) utilizando gaiolas metabólicas em trabalhos com asininos, observaram mudanças no comportamento dos animais e alterações nos coeficientes de digestibilidade.

Um dos inconvenientes da técnica de coleta total de fezes consiste no fato de que durante o período experimental, os animais ficam confinados em condições desfavoráveis à manutenção da espécie, levando a irregularidades fisiológicas com influência negativa sobre o processo digestivo. Outros fatores negativos seriam o de restringir o número de animais experimentais à disponibilidade de infra-estrutura, além de exigir mão-de-obra qualificada.

O período de coleta de fezes deve ter uma duração suficiente para reduzir ao máximo os erros resultantes da excreção irregular de fezes e da variação diária no comportamento doas animais (ARAUJO et al., 2003).

Alternativamente ao método da coleta direta, tem sido proposto o método dos indicadores, ou indireto, que é fundamentado no emprego de uma substância índice ou indicador que, ao ser ingerido na dieta, deve ser totalmente recuperada nas fezes 
(SILVA et al., 1968). Os indicadores podem ou não estar presentes naturalmente na dieta, subdividindo-se em internos e externos. Entre os indicadores internos têm sido estudados alguns componentes da fração fibrosa dos alimentos, como a fibra em detergente neutro, fibra em detergente ácido, lignina em detergente ácido, celulose potencialmente indigerível e cinza insolúvel em detergente ácido. Estes indicadores podem ser utilizados tanto na estimativa da produção fecal como dos coeficientes de digestibilidade e ingestão de alimentos (FREITAS et al., 2002).

Segundo Maynard et al. (1979), o indicador ideal para determinar a digestibilidade e a produção fecal deve possuir algumas propriedades fundamentais, como a indigestibilidade total, ser farmacologicamente inativo no trato digestivo, taxa de passagem uniforme, poder ser determinado quimicamente e, de preferência, ser uma substância naturalmente presente nos alimentos (OLIVEIRA et al., 2003).

\section{4. ÓXIDO CRÔMICO}

Dos indicadores externos o mais utilizado é o óxido crômico ( $\mathrm{Cr} 2 \mathrm{O} 3)$, sendo seu emprego bastante difundido para a estimativa da produção fecal, principalmente em ensaios de pastejo, pois permite estimar o consumo de forragem por meio da relação entre a produção fecal e a indigestibilidade da dieta (FREITAS et al., 2002).

Almeida et al. (1997), trabalhando com digestão pré-cecal em eqüinos, descreveram o óxido crômico como o mais adequado indicador para ensaios de digestibilidade, em comparação a fibra em detergente ácido (FDA), lignina e cinza insolúvel em detergente ácido (CIDA).

Sankhyan et al. (1999), obtiveram resultados semelhantes entre a digestibilidade de nutrientes estimada pelo oxido crômico e pela coleta total de fezes em carneiros.

Vários problemas têm sido relatados na literatura em relação ao uso do óxido crômico, como incompleta mistura com a digesta ruminal (COELHO DA SILVA et al., 1979), passagem mais rápida pelo rumem que o material fibroso (VAN SOEST, 1994) e possibilidade de acúmulo em alguma parte do trato digestivo (SCHINEIDER e FLATT, 1975). 
Recentemente, o $\mathrm{Cr}$ tem sido empregado de forma ligada à parede celular, num complexo denominado Cr-mordante (UDÉN et al., 1980; Van SOEST, 1994), cuja técnica de utilização conhecida como dose-pulso, é amplamente empregada em estudos de cinética de trânsito e consiste na aplicação de uma única dose com subseqüente amostragem fecal em tempos definidos, com a finalidade de caracterizar a curva de excreção do indicador nas fezes, posteriormente ajustada por meio de modelos matemáticos não lineares (DETMANN et al., 2001).

\subsection{INDICADORES INTERNOS}

Nas condições a campo, onde não é prática a adição de marcadores na dieta, a ocorrência natural de indicadores indigeríveis pode ser utilizada sem modificações na dieta normal, fornecendo assim, uma importante ferramenta para estudos de digestibilidade.

Van Soest (1993) relata que a lignina é o componente mais importante da parede celular secundária que limita a digestibilidade. Seu uso na nutrição, como é um componente indigerível, pode servir como indicador.

A lignina em detergente ácido (LDA) é um marcador de ocorrência natural em alimentos para eqüinos, já que é completamente indigerível. (MIRAGLIA et al., 1999)

A lignina é um polímero formado por três álcoois, p-coumaril, coniferil e sinapil, que se interligam numa malha complexa, resistente a hidrolise ácida e alcalina e a vários complexos enzimáticos, inclusive as enzimas microbianas e tissulares do trato gastrintestinal dos animais superiores (FUKUSHIMA 2003).

O alto índice de polimerização torna a lignina insolúvel e, portanto indigerível e não absorvida pelo organismo animal. Estas características a qualifica como potencial marcador interno para os ensaios de digestibilidade. A lignina ocorre naturalmente na parede celular vegetal e à medida que as plantas forrageiras amadurecem maior é a sua concentração, bem como seu efeito deletério sobre a utilização da parede celular. (VAN SOEST, 1994).

Fukushima e Savioli (2003) relatam que ruminantes podem utilizar a porção fibrosa de plantas forrageiras como fonte de energia. Entretanto, seu aproveitamento não pode ser considerado adequado, caso significativa porção seja excretada pelo 
animal. A lignina, ao se ligar quimicamente com os carboidratos da parede celular, é considerada o principal obstáculo à digestão da fibra (JUNG et al., 1996). Entretanto, os mecanismos de ação não estão completamente elucidados. As gramíneas, embora apresentem menores concentrações de lignina que as leguminosas, aparentemente, têm sua digestão acentuadamente diminuída (MOWAT et al., 1969). Outro exemplo reside na constatação de que nas forrageiras jovens, que caracteristicamente apresentam baixas concentrações de lignina, um ligeiro aumento nesta concentração acarreta em significativo efeito negativo na digestibilidade, enquanto que nas forrageiras maduras, que possuem elevados teores, um aumento nesta concentração acarreta pequenos decréscimos na digestibilidade (JUNG e VOGEL, 1986).

Dados variáveis de digestibilidade e recuperação de lignina são atribuídos aos métodos analíticos usados para a sua determinação. Fukushima et al. (1991) observaram que alfafa em estágio vegetativo mais jovem apresentava, cerca de $20 \%$ da fração lignina em detergente ácido insolúvel em solução de clorito de sódio, possivelmente cutina, sendo assim dependendo do método analítico empregado determinados alimentos ricos em cutina podem ter seus valores de lignina superestimados.

Para Muntifering (1982) entre as prováveis razões da ineficiência na recuperação da lignina estão a diferenciação dos monômeros fenólicos da lignina original (digestão verdadeira), a digestão aparente obtida pela formação de complexos solúveis lignina-carboidratos, a destruição parcial da lignina fecal pelos reagentes utilizados nos métodos analíticos e as diferenças físicas e químicas entre os alimentos e as fezes.

Revisando o uso da lignina como indicador Fahey e Jung (1983) verificaram que a lignina foi digerida em rações contendo $100 \%$ de forragem e até $90 \%$ de concentrado, podendo por conseqüência, ser utilizada como indicador somente quando apresentar evidências de sua alta recuperação fecal, sendo que restrições ao seu uso devem ser feitas de acordo com a digestibilidade desta substância contida nas plantas em estágio inicial de crescimento. Em gramíneas jovens e em espécies vegetais com baixas concentrações de lignina, o menor grau de polimerização pode proporcionar uma digestibilidade da ordem de 20 a $40 \%$ (VAN SOEST, 1994). 
Fonnesbeck (1969) trabalhando com eqüinos encontrou variações na digestibilidade da lignina em leguminosas de -15.60 a $4.8 \%$, e em gramíneas de 0 a $16.40 \%$.

Mauricio (1993) comparou os valores de digestibilidade de uma ração composta por feno de Coast cross e concentrado, estimada por meio da lignina, do óxido crômico e pelo método de coleta total. Os resultados mostraram que a lignina e o óxido crômico subestimaram os coeficientes de MS, PB, EB, FDN e FDA, devido as suas baixas recuperações.

Os indicadores cinza insolúvel em ácido (CIA), fibra em detergente ácido indigerível (FDAi) e celulose indigerível (CELi) têm apresentado estimativas próximas às do método de coleta total de fezes e, portanto, são considerados potenciais nas dietas para eqüinos.

Em estudos de digestão com eqüinos utilizando a CIA como indicador interno, alguns autores (CUDDERFORD e HUGUES, 1990; PEREIRA e QUEIROZ, 1997; MIRAGLIA et al., 1999; ARAÚJO et al., 2000) encontraram estimativas dos coeficientes de digestibilidade aparente dos nutrientes semelhantes às obtidas com o método de coleta total de fezes, com percentuais de recuperação fecal do indicador próximos a $100 \%$.

Estudando a CIA, Machado (1992) concluiu que o indicador foi eficiente em estimar a digestibilidade de nutrientes em eqüinos, com coeficientes semelhantes aqueles obtidos com a coleta total de fezes e, apresentar porcentagem de recuperação próxima a $100 \%$. Araújo (1999) chegou a este mesmo resultado quando forneceu $60 \%$ de feno de Coast cross e $40 \%$ de milho ou farelo de soja para eqüinos. Ambos os autores ressaltam, todavia, a necessidade de mais estudos nesta espécie a fim de avaliar com segurança o potencial deste indicador.

Sunvold e Cochran (1991) compararam o uso dos indicadores CIA e FDAi, entre outros, com a coleta total de fezes na estimativa da digestibilidade da matéria orgânica de diferentes forrageiras e relataram diferenças entre as estimativas obtidas com a FDAi e a coleta total de fezes, enquanto que a CIA não apresentou diferença significativa na estimativa da digestibilidade aparente da matéria orgânica dos fenos de gramíneas. Ferret et al. (1999) utilizaram a FDAi como indicador interno em ensaios de digestão com ovinos e não recomendam sua utilização, em razão da variação na sua taxa de recuperação fecal conforme o tipo de feno ingerido (STEIN et al., 2006). 
A recuperação de frações indigeríveis do alimento é a base para os indicadores internos, que são utilizados em estudos nos quais são necessárias estimativas de digestibilidade (VAN SOEST, 1994). O erro de amostragem pode ser reduzido se um componente indigerível de alta porcentagem na matéria seca puder ser encontrado. Nesse sentido, tem sido sugerido que as frações fibrosas indigeríveis do alimento sejam utilizadas com este propósito (LIPPKE et al., 1986).

A maioria das células epidermais das porções aéreas das plantas, como as folhas, frutos e caules, assim como algumas briófitas são recobertas por uma membrana extracelular contínua de lipídios polimerizados denominada cutícula. A composição desta estrutura varia amplamente entre as plantas, órgãos e estágios de crescimento e tem como função principal minimizar as perdas de água. A cutina é a maior constituinte (entre 40 a $80 \%$ do peso) da cutícula, e do ponto de vista químico é definida como uma rede polimérica de ácidos graxos oxigenados interligados (HEREDIA, 2003).

A cutina é um polímero ligado à parede celular utilizado como indicador, mas com poucas informações na literatura sobre as quantidades percentuais mínimas da dieta ou na digesta assim como sobre metodologias de determinação em laboratório (SILVA et al., 2006). 


\section{OBJETIVO}

O presente trabalho foi conduzido com o objetivo de avaliar a acurácia, a precisão e a robustez dos indicadores cutina, lignina em detergente ácido e óxido crômico na estimativa da digestibilidade aparente da matéria orgânica de dietas para eqüinos, em relação à coleta total de fezes. 


\section{MATERIAL E MÉTODOS}

A digestibilidade da matéria orgânica (DAMO) das dietas utilizadas foi estimada com o auxílio de indicadores internos (lignina em detergente ácido e cutina) e externo (óxido crômico). Então, as estimativas da DAMO foram comparadas à obtida pela técnica de coleta total de fezes e o uso dos indicadores de interesse foi avaliado quanto à sua acurácia, precisão e robustez.

Desta forma, descrição da metodologia foi dividida quanto à determinação da digestibilidade das dietas pelo método de coleta total de fezes, o emprego dos indicadores para o cálculo da DAMO predita, e por fim, sua avaliação.

\subsection{DETERMINAÇÃO DA DIGESTIBILIDADE APARENTE DA MATÉRIA ORGÂNICA PELA TÉCNICA DE COLETA TOTAL DE FEZES}

\subsubsection{Local}

O experimento foi conduzido nas dependências do setor de Eqüideocultura da Faculdade de Medicina Veterinária e Zootecnia da Universidade de São Paulo FMVZ/USP - e as análises químicas dos alimentos e fezes foram realizadas no Laboratório de Bromatologia do Departamento de Nutrição e Produção Animal, da mesma universidade, no campus administrativo de Pirassununga, SP.

\subsubsection{Animais e Instalações}

Foram utilizados quatro eqüinos machos, filhos do mesmo garanhão, sem raça definida, com idade aproximada de 10 meses e peso médio de $197 \mathrm{~kg}$ (170 kg a 216 kg), pertencentes à Prefeitura do Campus Administrativo de Pirassununga PCAPS. 
Todos foram vermifugados, pulverizados contra ectoparasitas, imunizados contra tétano e, então, alojados em baias individuais $(2,5 \mathrm{~m} \times 3,0 \mathrm{~m})$ devidamente identificadas, que possuíam porta em madeira formada por duas partes que possibilitavam movimento independente entre si. Nas baias, existiam bebedouros, cochos de alvenaria, separados para o fornecimento de volumoso e concentrado. $O$ piso era de cimento queimado sobre o qual foi colocada serragem de madeira como cama (maravalha).

\subsubsection{Delineamento Experimental e Alimentação}

Seguindo um delineamento em Quadrado Latino $4 \times 4$, os animais foram distribuídos aleatoriamente a um dos tratamentos abaixo:

AC: dieta contendo feno de alfafa disposto em cubos;

AR: dieta contendo feno de alfafa disposto em ramas;

$A C+O$ : dieta com feno de alfafa em cubos adicionado de óleo de soja refinado;

$\mathrm{AR}+\mathrm{O}$ : dieta com feno de alfafa em ramas adicionado de óleo de soja refinado.

O experimento foi realizado em quatro períodos com duração de onze dias cada, sendo que os oito primeiros dias foram para adaptação às dietas e os três subseqüentes, para colheita de fezes (ARAÚJO et. al., 2003). Das fezes colhidas, foi retirada uma parte para a determinação laboratorial dos indicadores cutina, LDA e óxido crômico.

A alimentação dos animais foi realizada duas vezes ao dia, sendo a ração total (feno + concentrado) dividida em partes iguais entre os dois horários (7 e 19 horas). A dieta foi fornecida em $2,5 \%$ do peso vivo com base na matéria seca, sendo composta por $40 \%$ de concentrado e $60 \%$ de volumoso. O concentrado foi fornecido em comedouro separado do volumoso e a água e o sal mineral ficaram disponíveis à vontade. O consumo de sal mineral não foi monitorado.

As dietas foram formuladas de acordo com as exigências para animais de crescimento moderado, que atingem $450 \mathrm{~kg}$ de peso quando adultos, conforme as recomendações descritas no NRC (1989). A composição química dos ingredientes, a 
participação dos ingredientes e a composição química de cada dieta são apresentados nas Tabelas 1, 2 e 3.

\subsubsection{Coleta Total de Fezes, Amostragem e Análises Químicas}

As coletas totais de fezes foram realizadas do $9^{\circ}$ ao $11^{\circ}$ dia experimental $(3$ períodos de 24 horas), com os animais mantidos nas baias sem cama. As fezes foram recolhidas do chão, pesadas e identificadas individualmente. Das fezes coletadas, após homogeneização, foram retiradas frações correspondentes a $10 \%$ do total, acondicionadas em sacos plásticos e congeladas a $-20^{\circ} \mathrm{C}$ para posteriores análises laboratoriais.

Tabela 1 - Composição química dos ingredientes com base na matéria seca Ingredientes

\begin{tabular}{lllll}
\cline { 2 - 4 } Nutrientes & Alfafa em cubos & Alfafa em ramas & Concentrado & Óleo de soja \\
\hline Matéria orgânica & 79,9 & 80,9 & 75,6 & 99,7 \\
Proteína bruta & 20,5 & 16,8 & 14,0 & - \\
Extrato etéreo & 1,63 & 1,35 & 3,59 & 99,7 \\
FDN & 39,4 & 51,2 & 39,5 & - \\
FDA & 32,8 & 39,9 & 15,7 & - \\
Matéria mineral & 9,81 & 8,99 & 15,0 & - \\
Ca & 1,31 & 1,42 & 2,19 & - \\
P & 0,35 & 0,19 & 0,89 & - \\
Cutina & 1,87 & 1,96 & 3,8 & - \\
Lignina & 8,15 & 11,83 & 7,51 & - \\
\hline
\end{tabular}


Tabela 2 - Composição de ingredientes das dietas experimentais com base na matéria original, em função dos tratamentos

\begin{tabular}{lcccccccc}
\hline & \multicolumn{2}{c}{ Alfafa em cubos } & \multicolumn{2}{c}{ Alfafa em ramas } & \multicolumn{2}{c}{ Concentrado } & \multicolumn{2}{c}{ Óleo de soja } \\
\cline { 2 - 9 } Tratamentos $^{1}$ & $(\%)$ & $(\mathrm{g})$ & $(\%)$ & $(\mathrm{g})$ & $(\%)$ & $(\mathrm{g})$ & $(\%)$ & $(\mathrm{g})$ \\
\hline $\mathrm{AC}$ & 55,6 & 2500 & - & - & 44,4 & 2000 & - & - \\
$\mathrm{AR}$ & - & - & 55,6 & 2500 & 44,4 & 2000 & - & - \\
$\mathrm{AC}+\mathrm{O}$ & 51,9 & 2500 & - & - & 41,5 & 2000 & 6,64 & 320 \\
$\mathrm{AR}+\mathrm{O}$ & - & - & 51,9 & 2500 & 41,5 & 2000 & 6,64 & 320 \\
\hline
\end{tabular}

${ }^{1} \mathrm{AC}$ : dieta contendo feno de alfafa disposto em cubos; AR: dieta contendo feno de alfafa disposto em ramas; AC + O: dieta com feno de alfafa em cubos adicionado de óleo de soja refinado; AR + O: dieta com feno de alfafa em ramas adicionado de óleo de soja refinado.

Tabela 3 - Composição química das dietas experimentais com base na matéria seca

\begin{tabular}{lcccc}
\hline & \multicolumn{4}{c}{ Tratamentos } \\
\cline { 2 - 5 } Nutrientes (\%) & AC & AR & AC + O & AR + O \\
\cline { 2 - 5 } Matéria orgânica & 87,9 & 88,3 & 88,8 & 89,2 \\
Proteína bruta & 17,6 & 15,5 & 16,3 & 14,4 \\
Extrato etéreo & 2,51 & 2,35 & 9,6 & 9,45 \\
FDN & 39,5 & 46,0 & 36,6 & 42,6 \\
FDA & 25,2 & 29,1 & 23,3 & 27,0 \\
Matéria mineral & 12,1 & 11,7 & 11,2 & 10,8 \\
Ca & 1,70 & 1,76 & 1,53 & 1,59 \\
P & 0,59 & 0,50 & 0,52 & 0,44 \\
\hline
\end{tabular}

${ }^{1}$ AC: dieta contendo feno de alfafa disposto em cubos; AR: dieta contendo feno de alfafa disposto em ramas; $A C$ + O: dieta com feno de alfafa em cubos adicionado de óleo de soja refinado; AR + O: dieta com feno de alfafa em ramas adicionado de óleo de soja refinado.

Ao final dos quatro períodos de colheitas, as amostras foram descongeladas à temperatura ambiente, homogeneizadas manualmente, pesadas e secas em estufa de ventilação forçada a $65^{\circ} \mathrm{C}$, por 72 horas. Logo após, foram moídas em moinhos com peneira de $1 \mathrm{~mm}^{2}$. Amostras compostas foram elaboradas, com base no peso seco, para cada animal e período. Todas as amostras, após serem moídas, foram acondicionadas em recipiente de vidro com tampa de polietileno e estocadas para devidas análises.

As concentrações de matéria seca, matéria orgânica, proteína bruta, matéria mineral e extrato etéreo dos ingredientes e das dietas, além do teor de matéria orgânica das fezes foram realizadas segundo a metodologia descrita por 
ASSOCIATION OF OFFICIAL ANALYTICAL CHEMIST - AOAC (1995). Para a determinação de fibra em detergente neutro e ácido dos ingredientes foi utilizada a metodologia descrita por Van Soest (1991).

A digestibilidade aparente da matéria orgânica da dieta foi obtida de acordo com Miraglia et al. (1999), sendo calculada como a porcentagem do nutriente digerido em relação à quantidade ingerida. Para a determinação da quantidade de nutriente digerido efetuou-se a subtração entre a quantidade de nutriente ingerido pela quantidade excretada nas fezes.

\subsection{EMPREGO DOS INDICADORES PARA O CÁLCULO DA DIGESTIBILIDADE APARENTE DA MATÉRIA ORGÂNICA PREDITA}

Em todos os dias de cada período experimental, junto às duas refeições que recebiam, foram adicionadas às dietas dos animais $10 \mathrm{~g}$ de óxido crômico misturado a pequenas quantidades de concentrado, totalizando $20 \mathrm{~g}$ do indicador por dia. A quantificação do cromo nas fezes se deu de acordo com a metodologia proposta por Udén et al. (1980) utilizando-se espectrofotometria de absorção atômica (aparelho Hitachi, modelo Z-8200).

A determinação das concentrações de lignina em detergente ácido (LDA) nos alimentos utilizados e nas fezes foi realizada conforme metodologia descrita por Van Soest (1964 apud) Silva (1990).

As análises do conteúdo de cutina nos ingredientes e fezes foram realizadas como proposto (Comunicação pessoal) ${ }^{1}$. A cutina foi determinada a partir da LDA, estando o técnico trabalhando com a proteção de luvas e em local bem ventilado.

Antes da confecção da LDA, no cadinho vazio, colocou-se 0,5 g de areia purificada. A partir daí, seguiu-se normalmente a determinação da LDA.

Em uma capela, colocou-se em banho-Maria uma vasilha de vidro refratária contendo ácido acético $1 \%$, a $70^{\circ} \mathrm{C}$, com aproximadamente $3,0 \mathrm{~cm}$ de altura, onde foram colocados os cadinhos com a massa de LDA e areia. Adicionou-se ácido

\footnotetext{
${ }^{1}$ FUKUSHIMA, R. S. (Faculdade de Medicina Veterinária e Zootecnia da Universidade de São Paulo, Pirassununga/SP, Brasil). Comunicação pessoal, 2007.
} 
acético $1 \%$ em cada cadinho, mexendo-se até que esta massa se fragmentou em pedaços menores.

Para cada cadinho, pesou-se separadamente três papelotes contendo $0,5 \mathrm{~g}$ de clorito de sódio $\left(\mathrm{NaClO}_{2}\right)$ cada. Adicionou-se o conteúdo do primeiro papelote, mexendo a mistura a cada 10 minutos, por meia hora, procedendo da mesma forma com o conteúdo do segundo e do terceiro papelote.

Realizou-se então a lavagem do material por diversas vezes com ácido acético $1 \%$, a $70^{\circ} \mathrm{C}$ e por último, com acetona. $\mathrm{O}$ cadinho foi seco em estufa a $65^{\circ} \mathrm{C}$ por 24 horas e a cutina determinada pela diferença de peso antes da LDA e depois deste procedimento, com base na matéria seca.

Os cálculos dos coeficientes de digestibilidade aparente da matéria orgânica obtidos pela técnica de indicadores foram realizados de acordo com o proposto por Church (1988):

$$
\text { Digestibilidade }=100-100 \times(A / B)
$$

Onde,

$A=\%$ de indicador na dieta ingerida;

$B=\%$ de indicador nas fezes.

\subsubsection{Equações}

As equações para o cálculo do NDT, ENN e predição da ED da dieta, foram utilizadas, conforme proposto por Pagan (1998):

$\mathrm{NDT} \%=\mathrm{PD} \%+\mathrm{EED} \% \times(2,25)+\mathrm{FDND} \%+\mathrm{ENND} \%$

$E N N \%=100-P B \%-E E \%-F D N \%-M M \%$

$\mathrm{ED}(\mathrm{kcal} / \mathrm{kg})=255+3660 \times \mathrm{NDT}$ 


\subsection{AVALIAÇÃO DOS INDICADORES}

O uso dos indicadores cutina, LDA e óxido crômico para a estimativa da DAMO em eqüinos foi avaliado quanto a acurácia, a precisão e a robustez.

A acurácia é a capacidade de direcionar a atenção para aquilo que se quer observar e a precisão é a maior ou a menor proximidade entre o valor observado e o valor estimado (STEIN et al., 2006).

A acurácia dos indicadores é avaliada através do viés médio. O viés é a diferença entre o valor predito pelo indicador e o valor observado pela coleta total de fezes. Portanto, o indicador mais acurado é aquele que possui um viés médio mais próximo do zero (Kohn et al., 1998). O cálculo do viés médio foi realizado segundo a fórmula abaixo:

Viés médio $=\frac{\sum(\text { predito }- \text { observado })}{n^{\circ} \text { observações }}$

A precisão é uma medida de dispersão entre os valores preditos e observados, ou seja, é a variabilidade média da distância entre o valor predito e o observado, ou ainda, a variabilidade dos vieses. Ela pode ser avaliada pela raiz quadrada média do erro de predição (RQMEP) ou pelo erro residual, cujos cálculos são dados a seguir:

RQMEP $=\sqrt{\frac{\sum(\text { predito }- \text { observado })^{2}}{n^{\circ} \text { observações }}}$

Erro residual $=\sqrt{\left[R Q M E P^{2}-(\text { viés_médio })^{2}\right]}$

Para se comparar a acurácia entre os indicadores, o viés médio foi submetido à análise de variância (teste F) e a comparação entre as médias foi realizada pelo teste de Tukey. Para a determinação da significância do valor médio do viés, ou seja, se foi significativamente diferente de zero, foi utilizado o teste $T$ para media igual a zero, pelo PROC UNIVARIATE (SAS, 1998). O nível de significância utilizado foi o de $5 \%$. 
Para se comparar a precisão entre os indicadores, os valores do erro residual foram submetidos ao teste de homogeneidade de variâncias (teste de Hartley), sendo comparados dois a dois, utilizando-se para tal, o PROC TTEST (SAS, 1998).

A fim de se avaliar o comportamento do erro de predição dos marcadores (vieses) em função da variação dos valores observados de DAMO, foi estimada a regressão entre os vieses e DAMO observado (coleta total de fezes) obtendo-se o viés linear (coeficiente angular), o coeficiente de determinação do modelo $\left(R^{2}\right)$ e a significância do viés, para cada indicador, através do procedimento REG do SAS (SAS, 1998).

Por sua vez, a avaliação da robustez de cada indicador foi obtida regredindo-se o viés contra as variáveis selecionadas (extrato etéreo na dieta, energia digestível na dieta e peso vivo) também pelo procedimento REG do SAS (SAS, 1998). A comparação entre os coeficientes angulares das retas foi realizada pela metodologia de comparação de retas, cujo princípio é avaliar a interação entre a variável selecionada e os indicadores, por meio da análise de variância (teste $\mathrm{F}$ ) pelo PROC GLM (SAS, 1998), sendo comparado dois a dois (MEYER, 2003).

Dados de digestibilidade foram submetidos à análise de variância de máxima verossimilhança restrita (REML) para um delineamento em quadrado latino $4 \times 4$ com parcelas sub-divididas, através do ajuste de um modelo linear com efeitos fixos de período de coleta, animal, processamento da alfafa (rama ou cubo), adição de óleo na dieta, método de determinação da produção fecal de matéria orgânica e a interação entre os dois últimos fatores. Para isso foi utilizado o procedimento Mixed do SAS (1998).

Para a obtenção das médias de digestibilidade aparente da matéria orgânica em função do método de determinação da produção fecal (coleta total e indicadores testados) e da adição ou não de gordura na dieta, foram utilizados procedimentos interativos de quadrados mínimos (LSMEANS) e suas comparações foram realizadas através de teste $\mathrm{T}$ ao nível de $5 \%$ de significância.

De forma a contextualizar o trabalho, apresentou-se na Tabela 4 o consumo de matéria seca diário da dieta e dos indicadores em função dos tratamentos utilizados. 
Tabela 4 - Consumo de matéria seca diário da dieta, concentração dos indicadores na dieta e ingestão diária dos indicadores em função dos tratamentos

\begin{tabular}{|c|c|c|c|c|c|}
\hline \multirow{2}{*}{ Consumo } & & \multicolumn{4}{|c|}{ Tratamento } \\
\hline & & Cubo & Cubo + Óleo & Rama & Rama + Óleo \\
\hline Dieta & Kg/dia & 4,06 & 4,37 & 4,06 & 4,38 \\
\hline \multicolumn{6}{|l|}{ Cutina } \\
\hline & $\%$ indicador $^{1}$ & 2,7 & 2,5 & 2,8 & 2,6 \\
\hline & g/dia ${ }^{2}$ & 110 & 110 & 113 & 113 \\
\hline \multicolumn{6}{|l|}{$\operatorname{LDA}^{3}$} \\
\hline & $\%$ indicador & 7,9 & 7,3 & 9,9 & 9,2 \\
\hline & g/dia & 319 & 319 & 402 & 402 \\
\hline \multicolumn{6}{|c|}{ Óxido crômico } \\
\hline & $\%$ indicador & 0,5 & 0,5 & 0,5 & 0,5 \\
\hline & g/dia & 20 & 20 & 20 & 20 \\
\hline
\end{tabular}

${ }^{1}$ concentração do indicador na dieta.

2 ingestão diária do indicador.

${ }^{3}$ lignina em detergente ácido. 


\section{RESULTADOS E DISCUSSÃO}

A estatística descritiva da recuperação fecal dos indicadores internos LDA e cutina e do indicador externo óxido crômico é apresentada na Tabela 5.

Tabela 5 - Recuperação fecal dos indicadores cutina, lignina em detergente ácido (LDA) e óxido crômico para estimativa da digestibilidade aparente da matéria orgânica (DAMO) em eqüinos

\begin{tabular}{|c|c|c|c|}
\hline \multirow{2}{*}{ Parâmetro } & \multicolumn{3}{|c|}{ Indicador } \\
\hline & Cutina & LDA & Óxido crômico \\
\hline \multicolumn{4}{|c|}{ Recuperação fecal } \\
\hline $\mathrm{n}$ & 16 & 16 & 16 \\
\hline média, \% 1, 2 & $151^{A}$ * & $100^{B \mathrm{~ns}}$ & $88^{B * *}$ \\
\hline máxima, \% & 196 & 135 & 98 \\
\hline mínima, \% & 76 & 67 & 73 \\
\hline desvio padrão & 33,4 & 20,7 & 6,90 \\
\hline $\mathrm{CV}^{3}$ & 22,1 & 20,7 & 7,87 \\
\hline
\end{tabular}

Houve diferença para a recuperação fecal entre os indicadores utilizados $(P<0,05)$. A recuperação para a cutina foi maior quando comparado à da LDA, do óxido crômico e da coleta total de fezes, enquanto que não houve diferença entre os dois últimos.

A média de recuperação fecal da cutina foi de 151\% (máxima de 196\% e mínima de $76 \%$ ), da lignina foi de $100 \%$ (máxima de $135 \%$ e mínima de $67 \%$ ) e do óxido crômico foi de $88 \%$ (máxima de $98 \%$ e mínima de $73 \%$ ).

Aplicando-se o teste t para média igual a 100, pode-se verificar que apenas para a LDA houve uma recuperação fecal adequada, ou seja, de $100 \%$, enquanto que as quantidades dos indicadores cutina e óxido crômico recuperadas nas fezes foram maior e menor que $100 \%$, respectivamente.

Oliveira et al. (2003) concluíram que o óxido crômico foi inadequado para as estimativas de digestibilidade em eqüinos, pois relacionaram estes resultados com a 
baixa recuperação do indicador nas fezes. A baixa recuperação fecal do óxido crômico em ensaios de digestão com eqüinos foi relatada por Pereira et al. (1995) e Mauricio et al. (1996), de 82,7 e 80\%, respectivamente, valores estes menores aos encontrados no presente estudo. Segundo Cuddeford e Hughes (1990), a excreção fecal diária do óxido crômico não é constante, o que provavelmente levou, no presente estudo, a recuperações sempre abaixo de $100 \%$, visto a amplitude de valores entre $98 \%$ e $73 \%$.

O coeficiente de variação dos indicadores LDA e cutina foram mais elevados (20,7\% e 22,1\%, respectivamente), quando comparados ao do óxido crômico, o que pode ser indicativo da inconstância de seus teores nas fezes ou ainda de falhas nos procedimentos laboratoriais. A última hipótese também pode ser considerada para explicar a alta recuperação da cutina nas fezes. Provavelmente, a técnica de determinação deste indicador utilizada neste trabalho quantificou erroneamente alguma fração do material analisado como sendo cutina, superestimando a concentração desta nas fezes.

Os coeficientes de digestibilidade aparente da matéria orgânica das dietas compostas por alfafa, com adição ou não de óleo de soja, obtidos pelos diferentes métodos, a probabilidade da existência de diferenças entre os métodos, assim como a da interação entre dieta e método, encontram-se na Tabela 6. 
Tabela 6 - Médias dos quadrados mínimos da digestibilidade aparente da matéria orgânica (\%) em função do método de determinação da produção fecal e das dietas utilizadas no experimento

Dieta

$$
\text { Método }
$$

Coleta total Cutina LDA Óxido crômico

\begin{tabular}{|c|c|c|c|c|c|c|}
\hline & & & & & média & $C V$ \\
\hline Com óleo & 70,2 & 79,1 & 68,6 & 66,5 & 71,1 & 7,45 \\
\hline Sem óleo & 65,9 & 76,7 & 66,3 & 60,3 & 67,3 & 10,9 \\
\hline média ${ }^{1}$ & $68,1^{B}$ & $77,9^{A}$ & $67,5^{B}$ & $63,4^{C}$ & & \\
\hline$C V^{2}$ & 5,67 & 5,31 & 7,20 & 7,67 & & \\
\hline Efeito & & & & & \multicolumn{2}{|c|}{$\operatorname{Pr}>F$} \\
\hline Dieta & & & & & \multicolumn{2}{|c|}{$<0,01$} \\
\hline Método & & & & & \multicolumn{2}{|c|}{$<0,0001$} \\
\hline Dieta x Método & & & & & \multicolumn{2}{|c|}{0,53} \\
\hline
\end{tabular}

Não foi objetivo discutir diferenças de digestibilidade entre dietas, mas sim mostrar que houve diferença na estimativa da DAMO da dieta entre os métodos, não ocorrendo interação com os tipos de dietas utilizadas. Isto quer dizer que independentemente do método utilizado, diferenças entre as dietas teriam sido observadas da mesma forma, sugerindo que em ensaios onde o objetivo é apenas avaliar diferenças qualitativas na digestibilidade entre dietas, todos os indicadores seriam adequados.

O valor médio obtido neste experimento para a DAMO pelo método da coleta total de fezes $(68,1 \%)$ foi igual ao obtido pelo indicador LDA $(67,5 \%)$. Ambos foram menores quando comparados ao estimado pela cutina $(77,9 \%)$ e maiores que o óxido crômico $(63,4 \%)(P<0,05)$. O menor valor estimado de DAMO pelo uso do óxido crômico está provavelmente relacionado à baixa recuperação deste indicador nas fezes, o que segundo Cuddeford e Hughes (1990), pode levar a erros nas estimativas da digestibilidade aparente dos nutrientes. A baixa recuperação levaria a uma superestimativa da produção fecal do nutriente, obtendo-se assim valores menores de digestibilidade aparente. 
Da mesma forma, a alta recuperação fecal da cutina pode ter levado a uma subestimativa da excreção da fração matéria orgânica pelas fezes, o que resultou em coeficientes de digestibilidade, aproximadamente, 10\% maiores. Ao contrário, a recuperação fecal da lignina sendo igual a 100\% (Tabela 5), permitiu valores estimados da DAMO iguais aos obtidos pelo método de coleta total de fezes (Tabela $6)$.

Para complementar uma análise simplista dos indicadores por apenas uma comparação entre médias das estimativas, no presente trabalho, apresentamos uma abordagem estatística baseada na avaliação dos conceitos de acurácia, precisão e robustez. Na Tabela 7 são apresentados parâmetros de acurácia e precisão dos indicadores.

Tabela 7 - Parâmetros de avaliação da acurácia e precisão da estimativa da digestibilidade aparente da matéria orgânica (DAMO) em eqüinos pelos indicadores cutina, lignina em detergente ácido (LDA) e óxido crômico

Parâmetro

$$
\text { Indicador }
$$

\begin{tabular}{ccc}
\hline Cutina & LDA & Óxido Crômico \\
\hline 12 & 12 & 16 \\
68,1 & 68,1 & 68,1 \\
77,2 & 66,7 & 63,4 \\
$9,97 \mathrm{~A}^{*}$ & $-0,56 \mathrm{~B}^{\mathrm{ns}}$ & $-4,69 \mathrm{~B}^{* *}$ \\
11,7 & 6,07 & 5,40 \\
7,19 & 7,02 & 3,14 \\
\hline
\end{tabular}

Regressão linear entre vieses e DAMO observadas

Viés linear ${ }^{5}$

\begin{tabular}{lll}
\hline$-1,28 \mathrm{~B}$ & $-1,02 \mathrm{~B}$ & $0,03 \mathrm{~A}$ \\
0,6263 & 0,4222 & 0,0017 \\
0,0022 & 0,0222 & 0,8798
\end{tabular}

$\mathrm{R}^{2}[6]$

0,0022

0,0222

0,8798

\footnotetext{
${ }^{1}$ Médias na mesma linha, seguidas de letras distintas, diferem entre si pelo teste HSD-Tukey, ao nível de $5 \%$ de significância.

${ }^{2}$ Probabilidade do teste $t$ para média $=0$. ns = não significativo $(P>0,05) ;{ }^{*} P<0,01 ;{ }^{*} P<0,0001$.

${ }^{3}$ Valores na mesma linha não diferem entre si pelo teste de Hartley ao nível de $5 \%$ de significância.

${ }_{5}^{4}$ Raiz quadrada da média do erro de predição.

5 Coeficiente angular do modelo de regressão entre vieses e DAMO. Valores na mesma linha, seguidos por letras distintas, diferem entre si pela metodologia de comparação de retas (análise de variância, interação método x DAMO significante ao nível de 5\%).

${ }^{6}$ Coeficiente de determinação do modelo linear de regressão vieses = DAMO.

${ }^{7}$ Probabilidade de aceitação da hipótese nula: Viés linear $=0$.
} 
Analisando-se os vieses médios, nota-se que o indicador cutina estimou a DAMO com maior viés $(9,97)$, seguido pelo óxido crômico $(-4,69)$ e pela LDA $(-0,56)$. Os vieses médios do óxido cromo e da LDA não diferiram $(P>0,05)$, entretanto apenas o viés médio da LDA foi considerado igual a zero pelo teste $t$, mostrando que a lignina em detergente ácido foi o indicador mais acurado para a estimativa da DAMO.

Quanto à precisão, óxido crômico apresentou raiz quadrada do erro de predição (RQMEP) e erro residual numericamente menor $(5,40$ e 3,14 , respectivamente) que cutina (11,7 e 7,19) e LDA $(6,07$ e 7,02). Uma vez que estes parâmetros relacionam-se à variabilidade encontrada para o erro de predição, podese sugerir que o óxido crômico foi o indicador mais preciso, apesar de não ter havido observado diferença estatística $(P>0,05)$.

Ao se regredir viés (DAMO predita - DAMO observada) versus DAMO observada, observa-se vieses lineares (coeficientes angulares das retas) de - 1,28 e - 1,02 para os indicadores cutina e LDA respectivamente e de 0,03 para óxido crômico. O viés linear do indicador óxido crômico diferiu dos vieses dos indicadores cutina e LDA, os quais não foram diferentes entre si $(P>0,05)$. Os vieses lineares da cutina e da LDA foram diferente de zero $(P<0,05)$, o que não ocorreu para o óxido crômico. Isto significa que o viés, ou o erro de predição, dos indicadores cutina e LDA é influenciado pelo DAMO da dieta. Para cutina e LDA o viés é maior para predição de DAMO observada com valores em torno de $60 \%$ e diminui aproximandose de zero quando estes valores estão perto de 70\% (Figuras 1 e 2). Já para o óxido crômico, o viés se mantém constante independente da DAMO observada (Figura 3). 
CUTINA

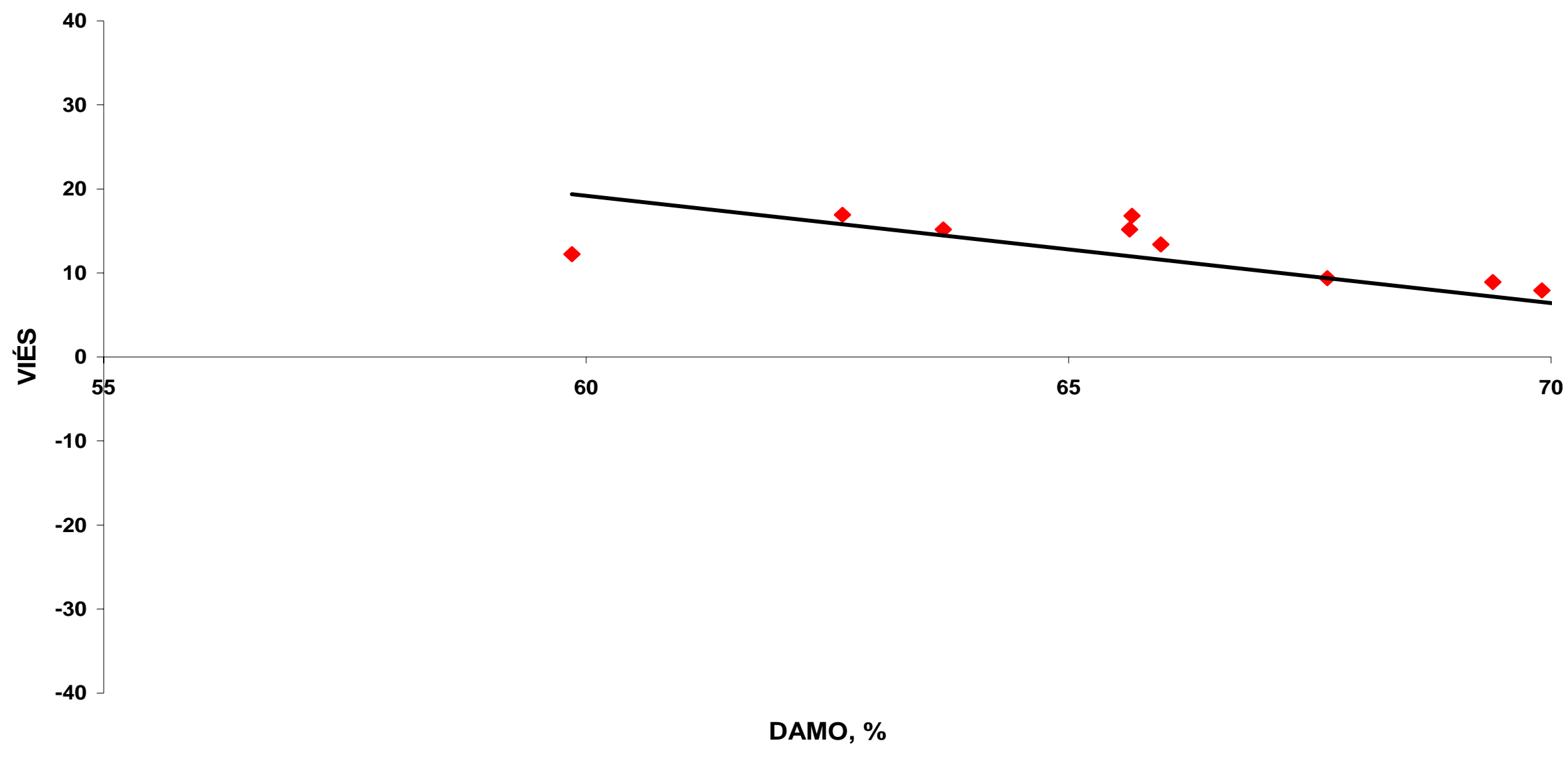

- DAMS observada — Linear (DAMS observada)

Figura 1 - Regressão entre vieses e digestibilidade aparente da matéria orgânica observada (DAMO) em eqüinos para o indicador cutina. 


\section{LDA}

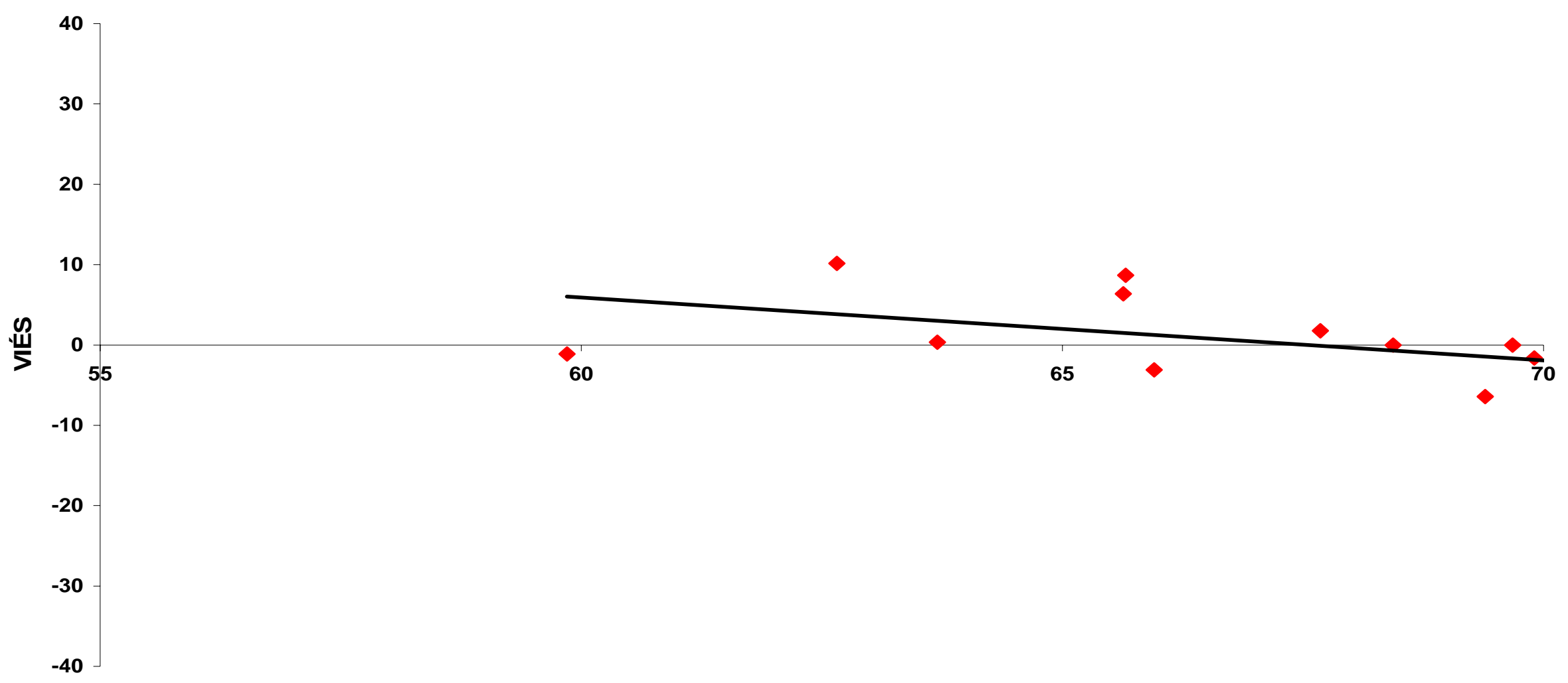

DAMO, \%

- DAMS observada L Linear (DAMS observada)

Figura 2 - Regressão entre vieses e digestibilidade aparente da matéria orgânica observada (DAMO) em eqüinos para o indicador lignina em detergente ácido (LDA). 


\section{ÓXIDO CRÔMICO}

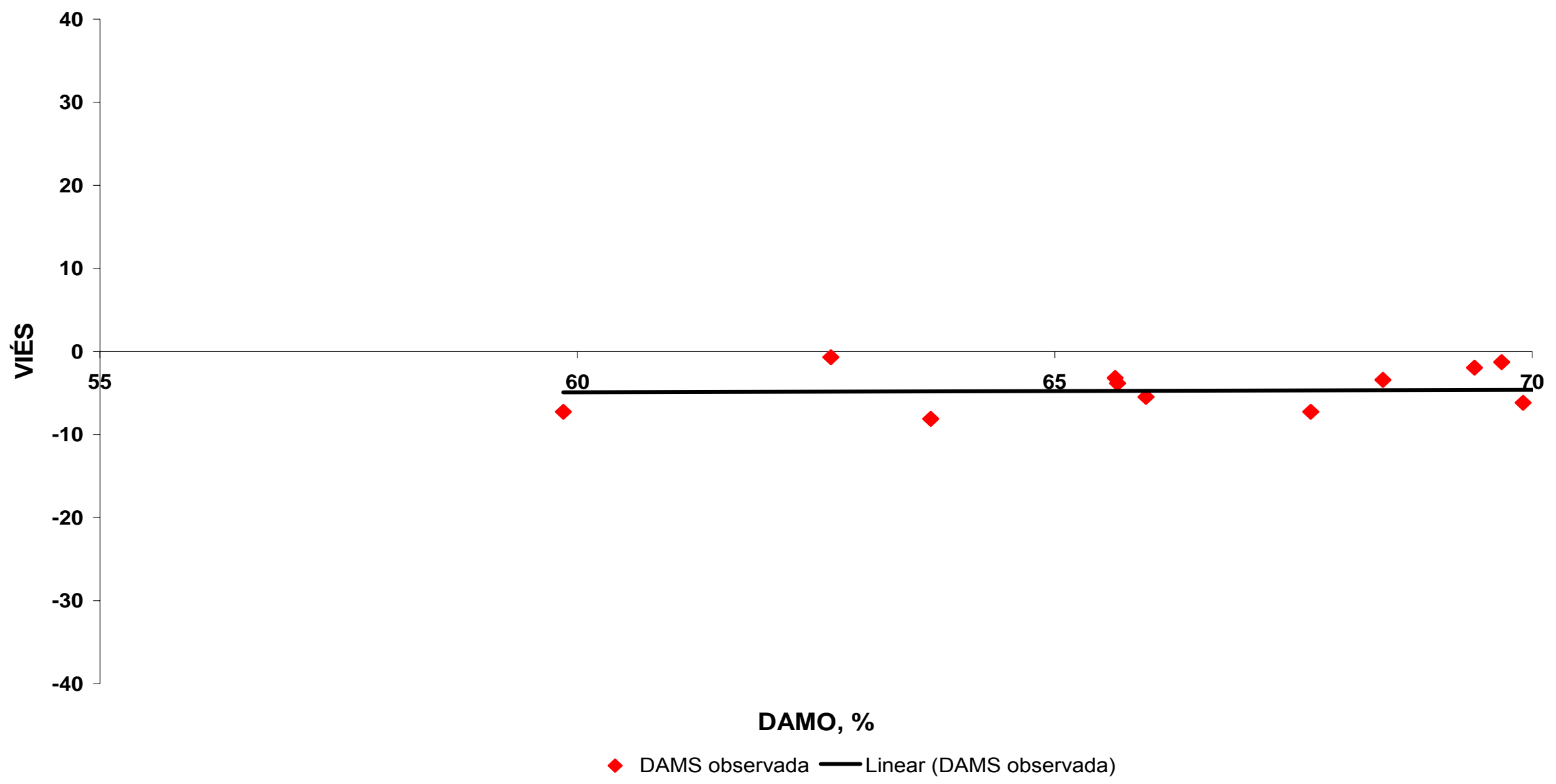

Figura 3 - Regressão entre vieses e digestibilidade aparente da matéria orgânica observada (DAMO) em eqüinos para o indicador óxido crômico. 
Entretanto, valores médios de recuperação fecal do óxido crômico de 100\% foram relatados por Almeida et al. (1997) que consideraram este indicador como o mais adequado para ensaios de digestibilidade em eqüinos, em comparação com a fibra em detergente ácido (FDA), LDA e cinza insolúvel em detergente ácido (CIDA), o que discorda com os resultados encontrados pelo presente trabalho, uma vez que pela análise de acurácia e pela recuperação fecal do indicador a lignina foi a mais adequada.

Gobesso (2001) também obteve valores subestimados para digestibilidade aparente da matéria orgânica, estimada pelo indicador óxido crômico em eqüinos alimentados com dietas compostas de concentrado a base de milho e feno de gramínea provavelmente devido a uma recuperação fecal daquele indicador menor que $100 \%$. Já Vasconcellos (2004), encontrou digestibilidade superestimada pelo mesmo indicador nos tratamentos onde os valores de produção fecal foram subestimados.

O indicador óxido crômico foi testado em experimentações administrado via sonda naso-gástrica, através de cápsulas, conjuntamente com pequena parcela de concentrado ou até mesmo adicionado durante o processo de fabricação do concentrado comercial, com diferentes resultados nas taxas de recuperação. Neste trabalho, o indicador foi previamente pesado e fornecido juntamente com a fração concentrada da dieta. Este procedimento pode ter interferido na taxa de recuperação deste indicador na dieta, uma vez que parte dele pode ter sido perdida ou aderida ao cocho de alvenaria. Cudderford (1990) enfatiza que as perdas advindas da administração e a excreção irregular em relação à ingestão, são problemas comuns em ensaios de digestibilidade que utilizam o óxido crômico como indicador externo.

Por outro lado, Mauricio et al. (1996) avaliaram dietas mistas com feno de Coast cross e concentrado para eqüinos utilizando a lignina na estimativa do coeficiente de digestibilidade aparente da matéria orgânica e observaram que os coeficientes de digestibilidade de FDN e FDA estimados pela lignina foram inferiores aos observados utilizando coleta total de fezes.

De acordo com Fahey e Jung (1983), a lignina pode ser utilizada como indicador apenas quando não houver evidências de alta recuperação fecal, o que aconteceu no presente estudo, já que este indicador apresentou recuperação igual a $100 \%$. 
Vasconcellos et al. (2007), compararam os métodos de coleta total de fezes com os indicadores óxido crômico, cinzas insolúveis em ácido e lignina na determinação dos coeficientes de digestibilidade aparente de nutrientes para gatos. A taxa de recuperação fecal da lignina foi altamente variável entre as quatro dietas estudadas, o que resultou num coeficiente de variação de $53,4 \%$, indicando que se trata de uma substância índice inadequada, que pode sub ou superestimar a digestibilidade dos alimentos. As diferenças entre as ligninas presentes no sorgo, milho, quirera de arroz e farinha de mandioca, bem como a reação destas ao tratamento de extrusão, podem ter sido responsáveis pela variação nas taxas de recuperação deste indicador

Correa et al. (2007) estudaram a lignina em detergente ácido como indicador interno na estimativa da digestibilidade aparente de três tipos de silagens (silagem de sorgo, silagem de sorgo aditivada com fubá e silagem de sorgo aditivada com Lacto Silo) em ovinos e concluíram que a lignina não se mostrou eficiente como indicador para os componentes nutritivos estudados.

Alguns autores sugerem que não se utilize a LDA como indicador interno (COCHRAN et al., 1988; TAMMINGAN et al., 1989) ou que seu uso seja limitado a dietas que contenham mais de $5 \%$ de lignina na matéria seca. Krysl et al. (1988) e Judkins et al. (1990) recomendam a LDA como indicador interno em determinados tipos de dieta. Em concordância com estes últimos autores, Ferret et al. (1999) concluíram que a LDA, entre vários indicadores testados, foi o melhor para estimar a digestibilidade aparente de matéria seca em dieta a base de alfafa.

A composição química da lignina nos alimentos é bastante variável, uma vez que este polímero é composto por várias unidades de p-cumaril álcool, coniferil álcool e sinapil álcool, que variam amplamente em proporções de acordo com a região anatômica em que a lignina está presente na planta, estágio de maturidade e entre os diferentes vegetais. Desta forma, pode ser normal a grande variedade de resultados na literatura devida principalmente à diferença entre dietas, ingredientes e protocolos laboratoriais utilizados pelos experimentos.

Dificuldades foram encontradas em relação à comparação de nossos resultados devido a poucos estudos terem sido publicados até então avaliando a utilização da cutina como marcador para estimar digestibilidade de frações de dietas para animais. Um estudo encontrado foi o de Silva et al. (2006), no qual foi utilizado esta fração para o estudo da digestibilidade de dietas contendo diferentes fontes 
protéicas e níveis de casca de soja. Os autores se referem neste trabalho a uma investigação anterior (Silva et al., 2002), realizada pelos mesmos, a qual teria observado uma "minimização das estimativas da digestibilidade da matéria seca" em dietas para bovinos. Entretanto, não foi possível encontrar naquele trabalho, qualquer resultado que sustentasse esta afirmação.

Avaliações da eficácia da utilização de óxido crômico e lignina para a estimativa da digestibilidade de frações de dietas para animais podem ser facilmente encontrados.

No trabalho de Brito et al. (2007), avaliou-se em bovinos o uso da FDA indigerível e do óxido crômico para a estimativa da digestibilidade aparente das frações de dietas variando a concentração de proteína bruta e de energia metabolizável. Os autores não verificaram interação entre indicadores e dieta para a estimativa da DAMO, sugerindo que, assim como neste estudo, o óxido crômico é robusto quanto à variação de alguns aspectos nutricionais da dieta utilizada.

Ao contrário, Oliveira Júnior et al. (2004), avaliando o uso do óxido crômico, FDN indigerível e lignina na estimativa da DAMO em bovinos, observaram uma interação entre dieta e indicador, em função da fonte de proteína utilizada na ração.

$\mathrm{Na}$ Tabela 8 é apresentada a avaliação da robustez (coeficiente angular, $\mathrm{R}^{2} \mathrm{e}$ probabilidade) das estimativas da digestibilidade aparente da matéria orgânica (DAMO) em eqüinos, através dos indicadores cutina, lignina em detergente ácido (LDA) e óxido crômico. Nas Figuras de 4 a 12, podemos observar o comportamento dos vieses em função da variação do extrato etéreo e energia da dieta e também do peso vivo animal, para cada indicador. 
Tabela 8 - Avaliação da robustez (coeficiente angular, $\mathrm{R}^{2}$ e probabilidade) das estimativas da digestibilidade aparente da matéria orgânica (DAMO) em eqüinos, através dos indicadores cutina, lignina em detergente ácido (LDA) e óxido crômico

Parâmetro

Indicador

Cutina LDA Óxido Crômico

EE na dieta, $\%{ }^{1}$

Coeficiente angular ${ }^{2}$

$\begin{array}{ccc}-0,31665 & -0,37486 & 0,2638 \\ 0,0294 & 0,0430 & 0,1192 \\ 0,5942 & 0,5177 & 0,1902\end{array}$

ED na dieta, Mcal $/ \mathrm{kg}^{5}$

Coeficiente angular

$-11,9548 B$

$-5,98039 A B$

$4,2729 \mathrm{~A}$

$\mathrm{R}^{2}$

0,2397

0,0627

0,1659

$\operatorname{Pr}>|\mathrm{t}|$

0,1062

0,4325

0,1174

Peso vivo animal, $\mathrm{kg}$

Coeficiente angular

$\begin{array}{lll}0,0665 & 0,1395 & 0,01725 \\ 0,0204 & 0,0696 & 0,0093 \\ 0,6577 & 0,4074 & 0,7228\end{array}$

$\mathrm{R}^{2}$

1 Teor de extrato etéreo dietético, com base na matéria seca.
2 Estimativa do coeficiente angular da equação linear de regressão entre os vieses e a respectiva variável independente. Valores na mesma linha foram comparados pela metodologia de comparação da inclinação de retas (análise de variância, interação vieses $x$ variável independente significante ao nível de $5 \%$ ) e quando seguidos de letras distintas, diferem estatisticamente entre si.

${ }^{3}$ Coeficiente de determinação do modelo de regressão linear entre vieses e a variável independente estudada.

${ }^{4}$ Probabilidade de aceitação da hipótese nula: coeficiente angular $=0$.

${ }^{5}$ Teor de energia digestível na dieta, com base na matéria seca.

Não houve diferença entre os coeficientes angulares da regressão dos vieses dos indicadores estudados e as variáveis extrato etéreo na dieta e peso vivo animal $(P>0,05)$, além de que todos não diferiram de zero pelo teste $t(P>0,05)$. Tal fato mostra que os indicadores foram robustos quanto à variação do EE e ED na dieta e PV dos animais utilizados, mantendo sua capacidade de predição da DAMO frente à amplitude de valores das variáveis independentes de interesse.

O mesmo ocorreu para a robustez dos indicadores quanto à energia digestível da dieta, independentemente dos coeficientes angulares da regressão terem diferido entre si $(P<0,05)$, com o óxido crômico apresentando maior valor, seguido por LDA e cutina. Desta forma, pode-se dizer que os indicadores cutina, LDA e óxido crômico 
se mostraram robustos para todas as variáveis testadas (EE, ED na dieta e peso vivo), uma vez que não sofreram influência das mesmas $(P>0,05)$. 


\section{CUTINA}

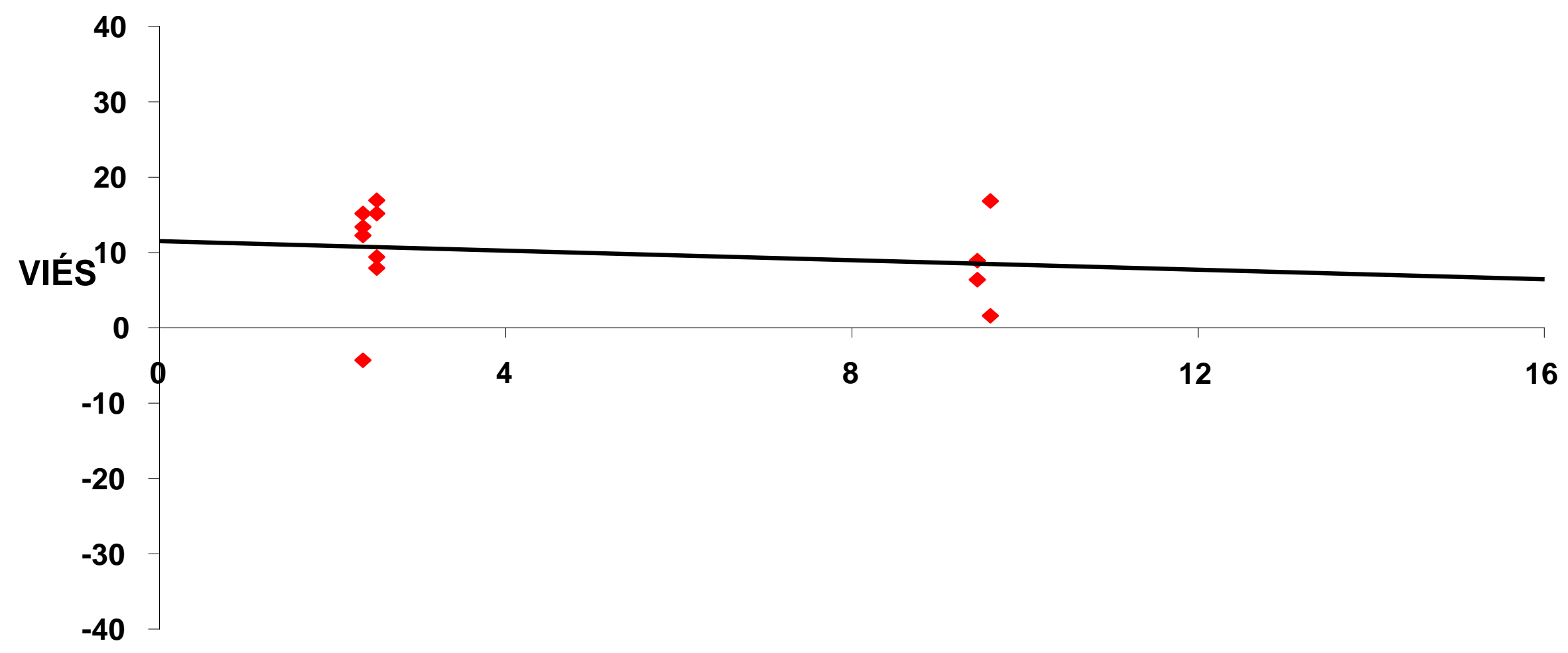

\section{EE NA DIETA, \%}

Figura 4 - Regressão linear entre os vieses da predição da digestibilidade aparente da matéria orgânica em eqüinos pelo indicador cutina e teores de extrato etéreo (EE) na dieta. 


\section{LDA}

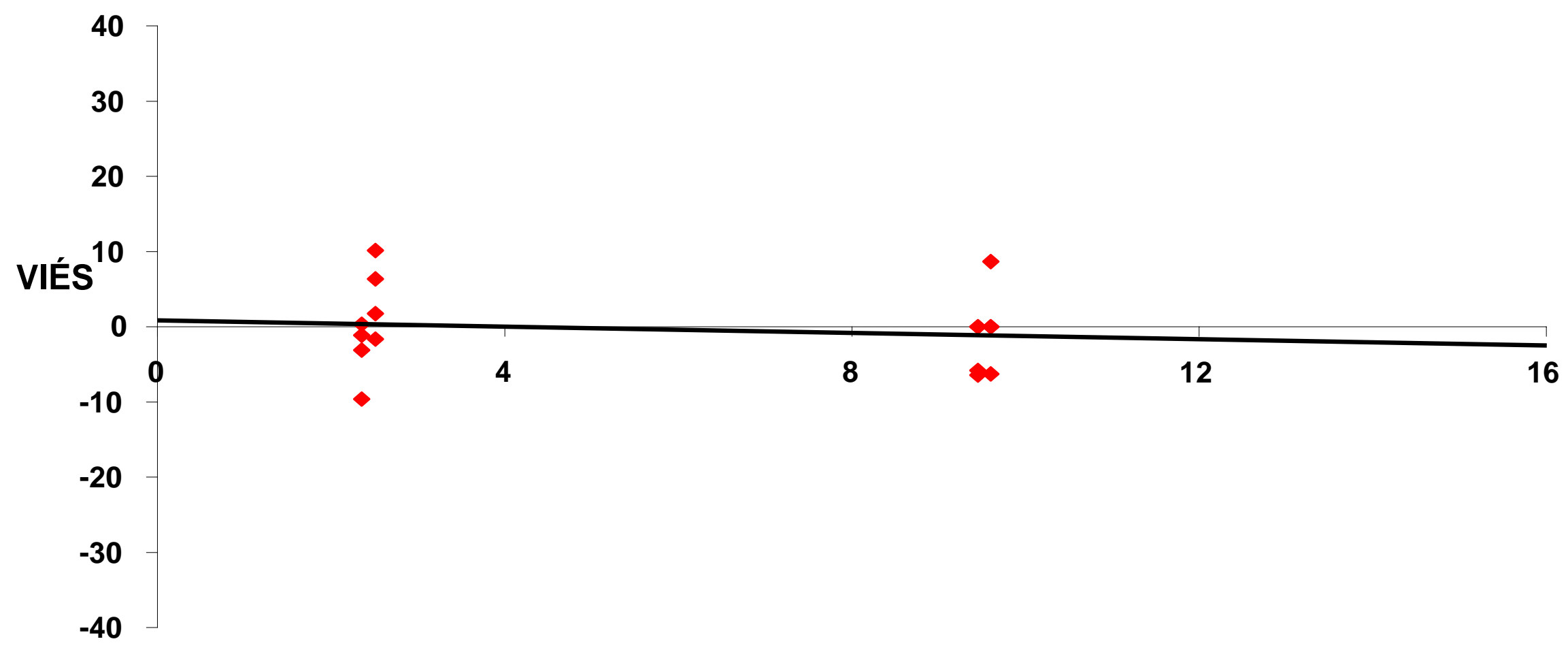

EE NA DIETA, \%

Figura 5 - Regressão linear entre os vieses da predição da digestibilidade aparente da matéria orgânica em eqüinos pelo indicador lignina em detergente ácido (LDA) e teores de extrato etéreo (EE) na dieta. 


\section{ÓXIDO CRÔMICO}

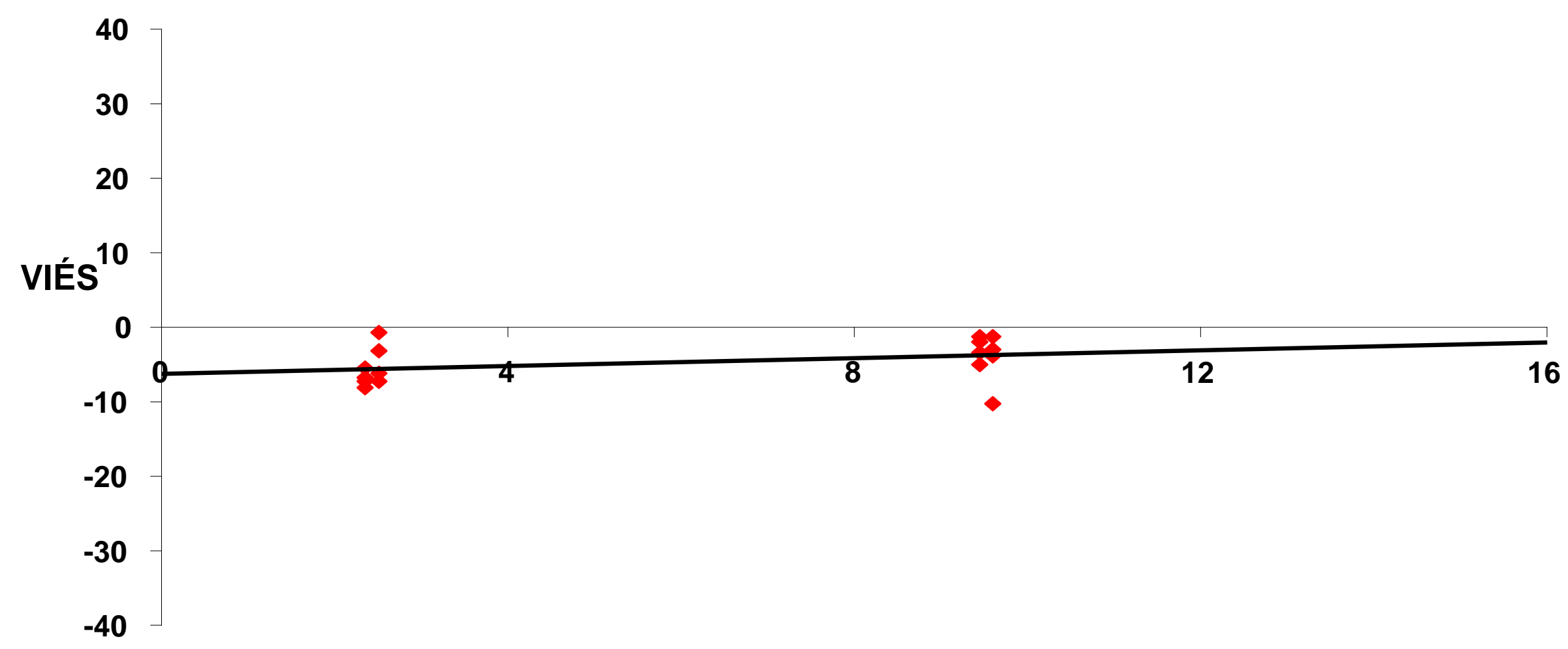

EE NA DIETA, \%

Figura 6 - Regressão linear entre os vieses da predição da digestibilidade aparente da matéria orgânica em eqüinos pelo indicador óxido crômico e teores de extrato etéreo (EE) na dieta. 


\section{CUTINA}

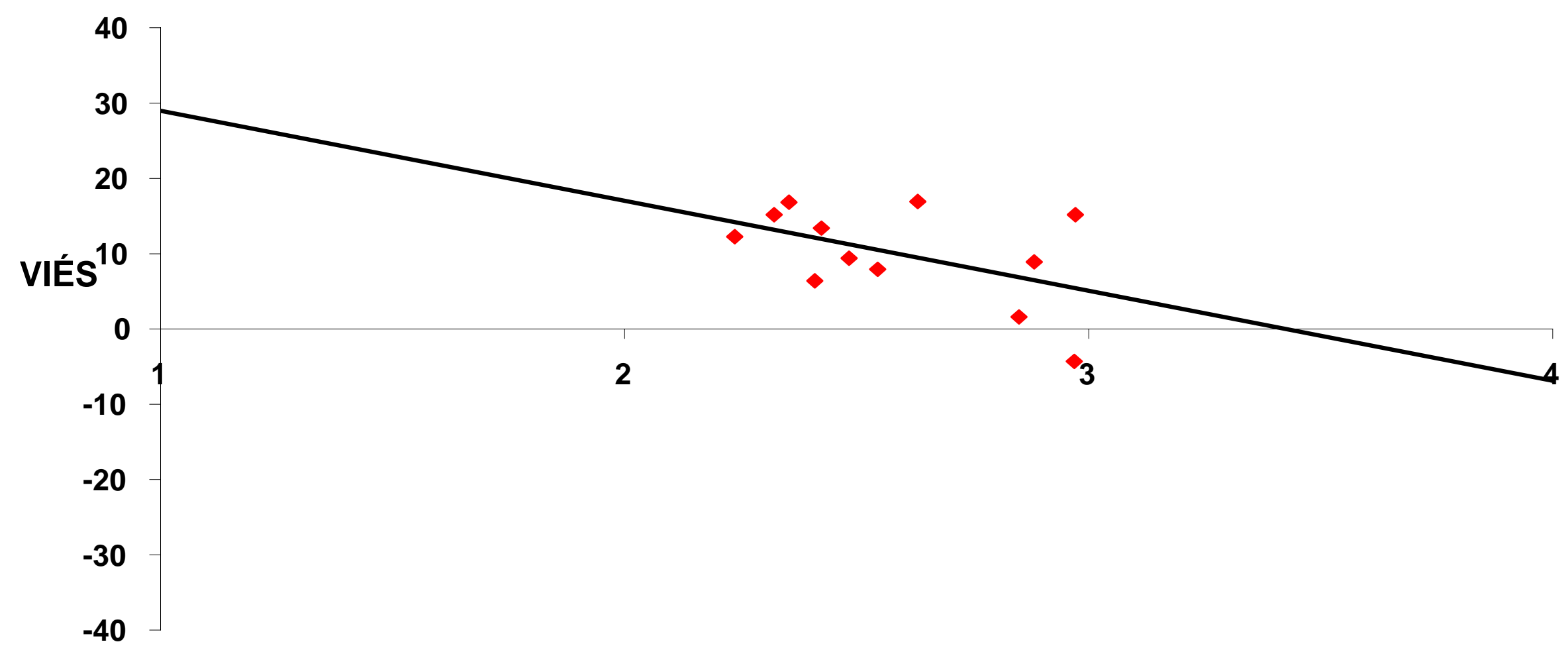

ED NA DIETA, Mcal/kg

Figura 7- Regressão linear entre os vieses da predição da digestibilidade aparente da matéria orgânica em eqüinos pelo indicador cutina e teores de energia digestível (ED) na dieta. 


\section{LDA}

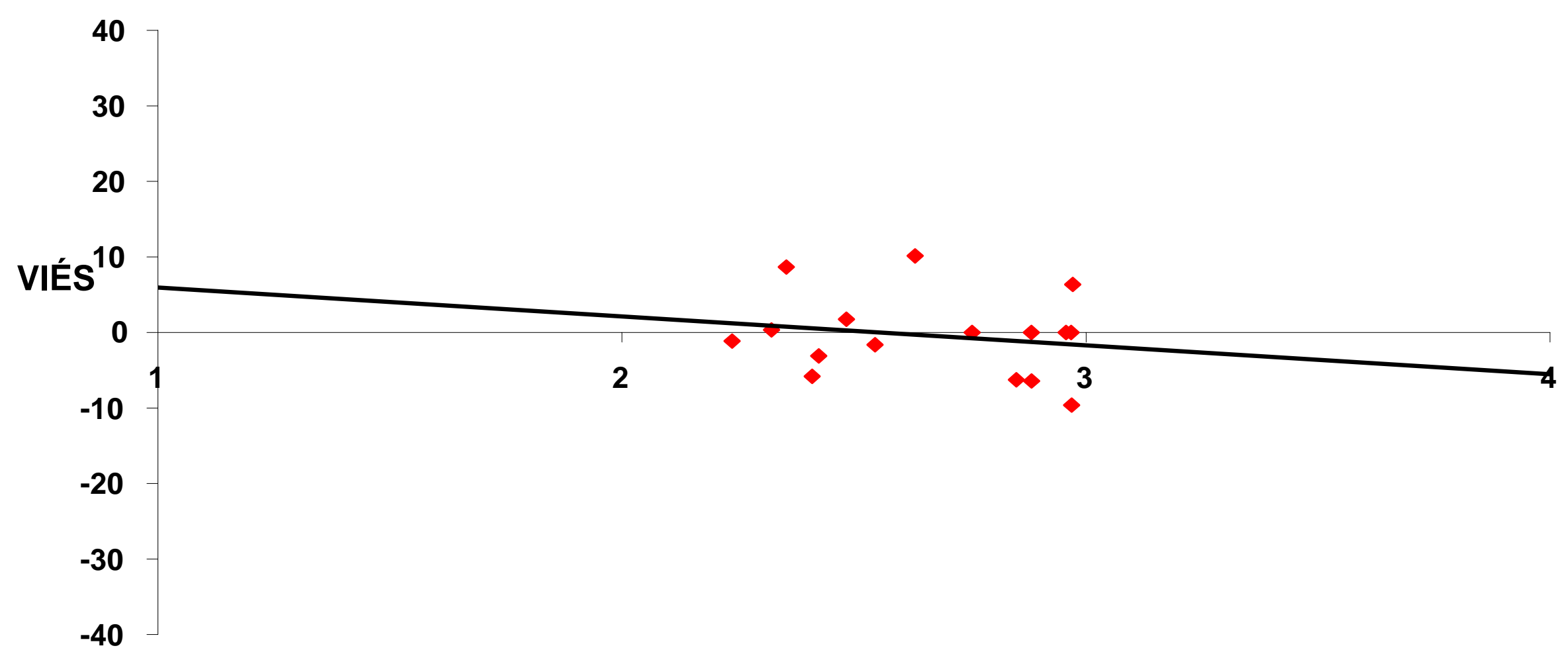

ED NA DIETA, Mcal/kg

Figura 8 - Regressão linear entre os vieses da predição da digestibilidade aparente da matéria orgânica em eqüinos pelo indicador lignina em detergente ácido (LDA) e teores de energia digestível (ED) na dieta. 


\section{ÓXIDO CRÔMICO}

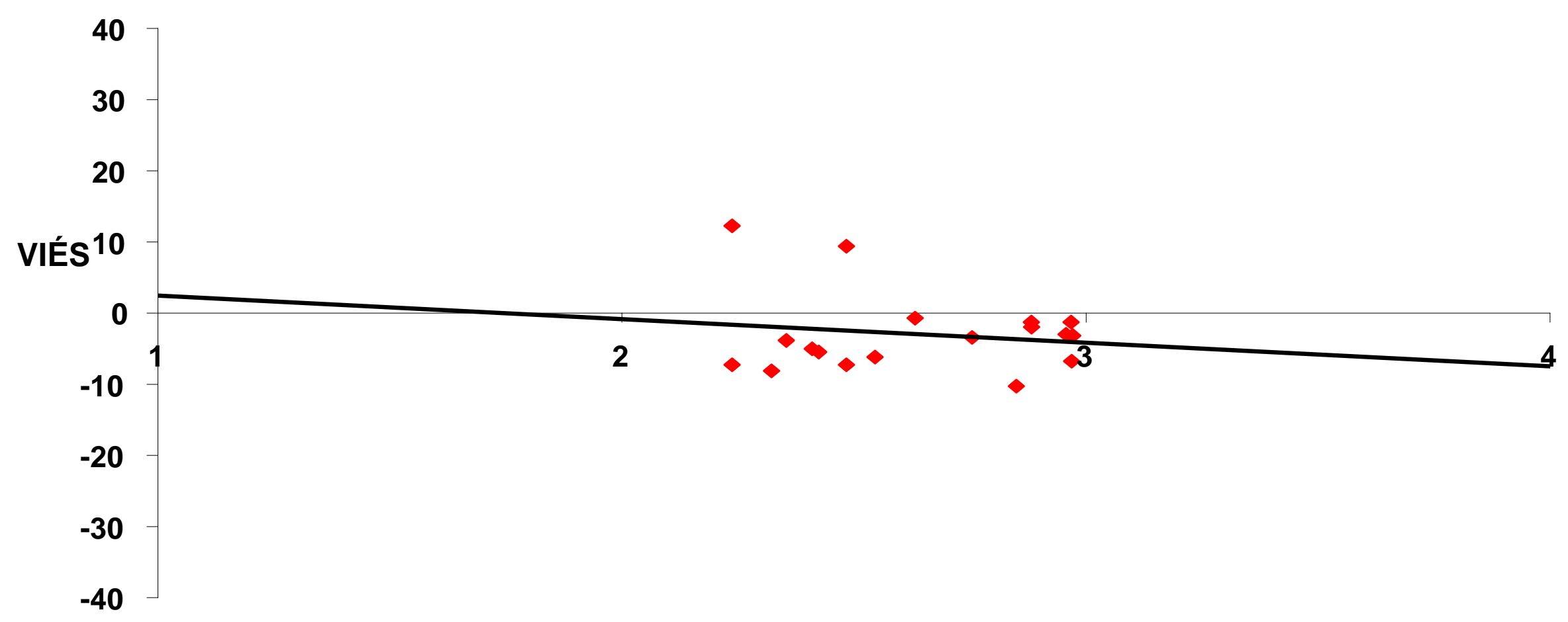

ED NA DIETA, Mcal/kg

Figura 9 - Regressão linear entre os vieses da predição da digestibilidade aparente da matéria orgânica em eqüinos pelo indicador óxido crômico e teores de energia digestível (ED) na dieta. 


\section{CUTINA}

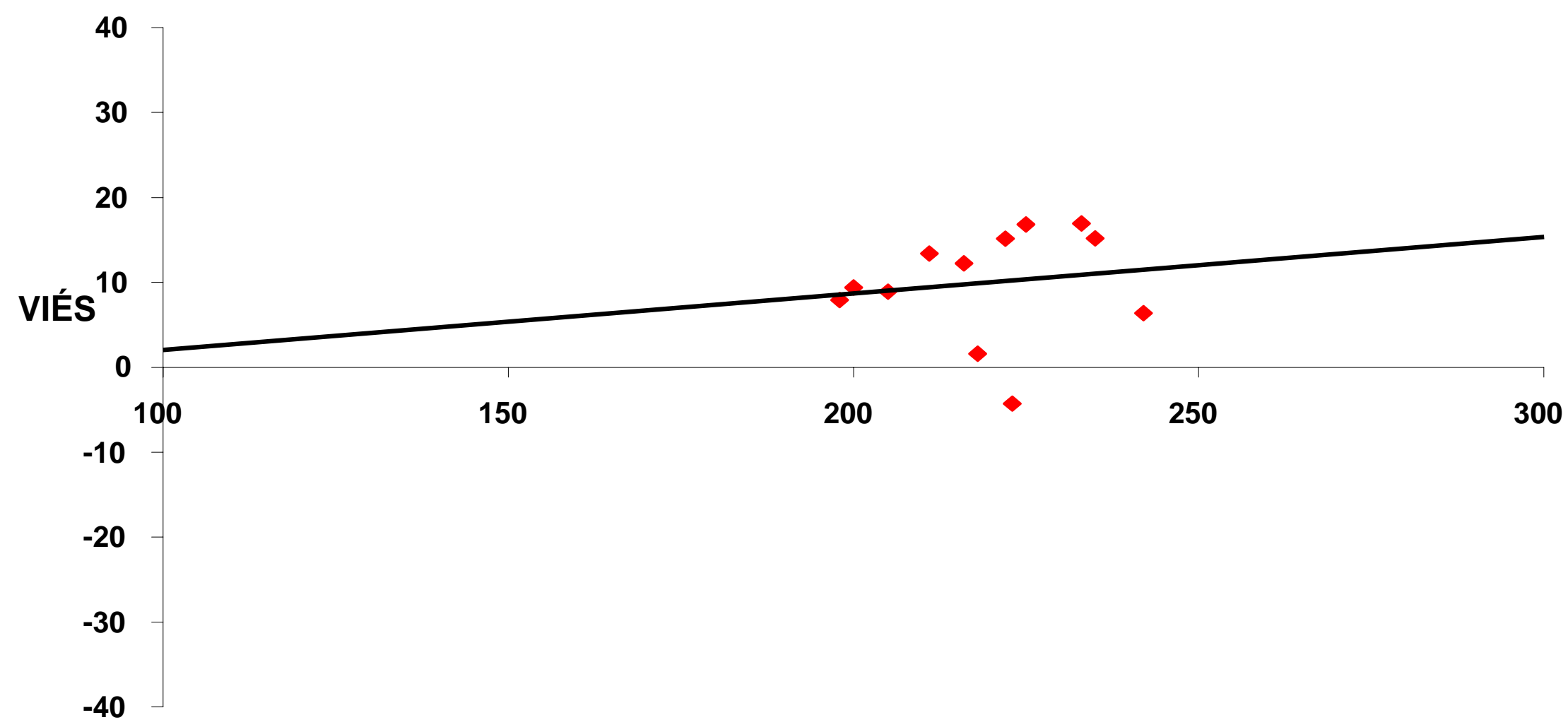

$\mathrm{PV}, \mathrm{kg}$

Figura 10 - Regressão linear entre os vieses da predição da digestibilidade aparente da matéria orgânica em eqüinos pelo indicador cutina e peso vivo (PV). 


\section{LDA}

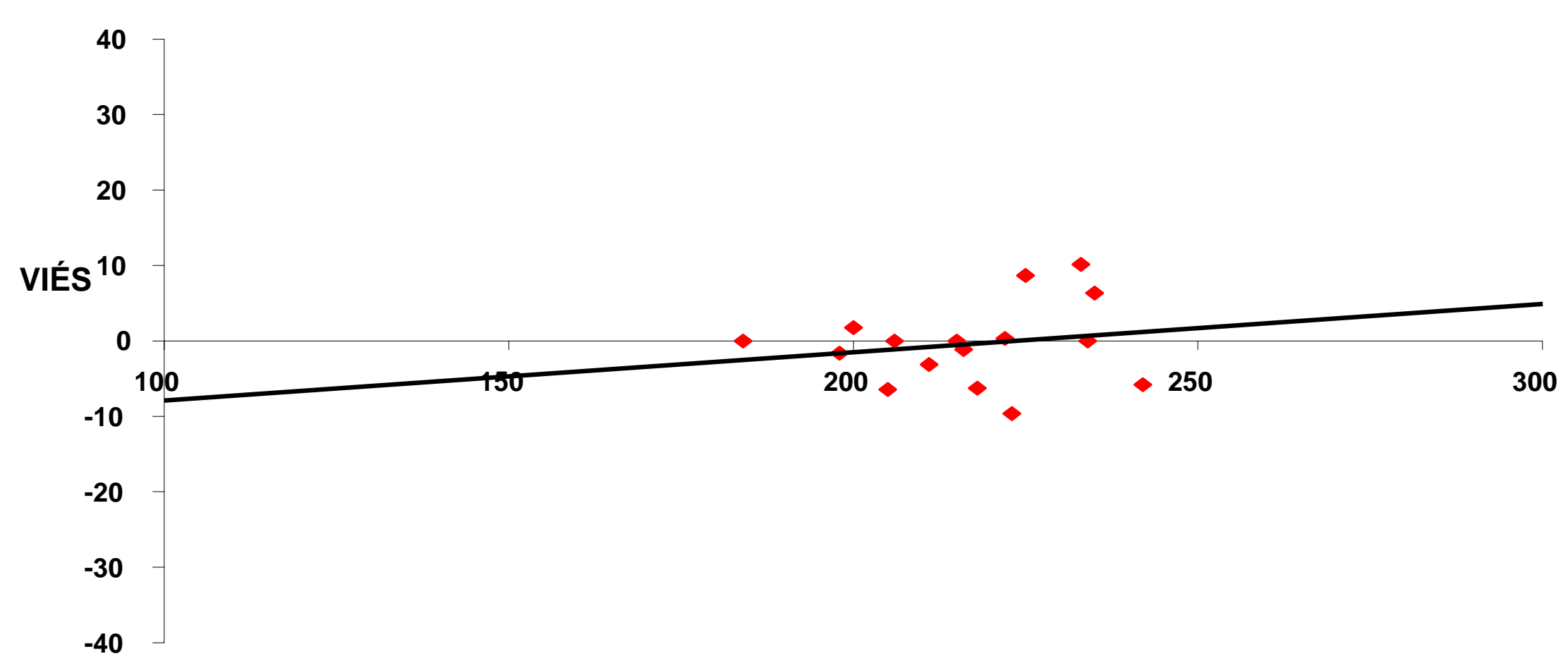

PV, kg

Figura 11 - Regressão linear entre os vieses da predição da digestibilidade aparente da matéria orgânica em eqüinos pelo indicador lignina em detergente ácido (LDA) e peso vivo (PV). 


\section{ÓXIDO CRÔMICO}

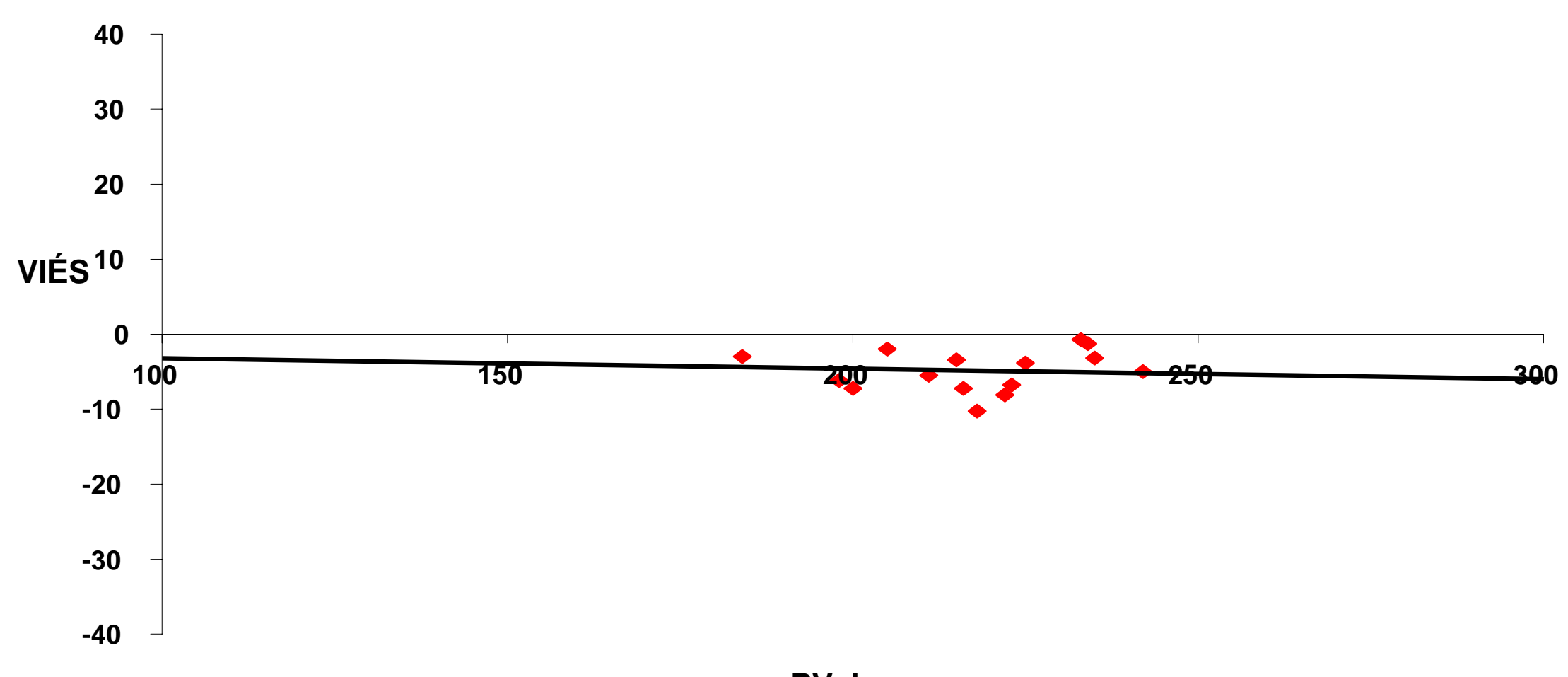

PV, kg

Figura 12 - Regressão linear entre os vieses da predição da digestibilidade aparente da matéria orgânica em eqüinos pelo indicador óxido crômico e peso vivo (PV). 
Poucos estudos realizaram o mesmo tipo de abordagem estatística para a avaliação de indicadores, podendo-se destacar o trabalho de Stein et al. (2006). Os autores observaram que os indicadores utilizados para a estimativa da digestibilidade da matéria seca em eqüinos foram robustos quanto a variações na dieta e características dos animais utilizados (peso vivo e idade). Tal relato concorda com os achados no presente trabalho. Stein e colaboradores ainda verificaram que os indicadores utilizados (FDAi, celulose indigestível e cinzas indigestíveis em detergente ácido) apresentaram viés linear significativo $(P<0,05)$, o que vai de acordo com os achados por nós para cutina e lignina. 


\section{CONCLUSÃo}

Segundo o modelo de avaliação utilizado, conclui-se que o indicador interno cutina e o indicador externo óxido crômico não se mostraram eficientes para estimar a digestibilidade aparente da matéria orgânica de dietas para eqüinos compostas por alfafa em rama, alfafa em cubos, concentrado e óleo de soja.

Como a cutina começa neste momento a ser testada como indicador interno em eqüinos, recomenda-se que novos estudos sejam conduzidos, com outros tipos de dietas, com a finalidade de validar seu uso nesta espécie animal.

$O$ indicador interno LDA apresentou melhor recuperação fecal e maior acurácia, sendo assim, considerado, nas condições que foram desenvolvidas este experimento, o mais adequado para estimar a digestibilidade aparente da matéria orgânica, em comparação com a coleta total de fezes. 


\section{REFERÊNCIAS}

AOAC. ASSOCIATION OF OFFICIAL ANALYTICAL CHEMISTS. Official methods of analysis. 16th ed. Arlington: AOAC International, 1995. 2 v. p.1025.

ALMEIDA, F. Q.; VALADARES FILHO, S. C.; LEÃO, M .l. et al. Digestão pré-cecal em eqüinos: 2 - Estimativa do fluxo de digesta ileal com indicadores externo e internos. In: Reunião da SBZ, 34., 1997, Juiz de Fora. Anais... Juiz de Fora: SBZ, 1997.

ARAUJO K. V. Métodos para determinação da digestibilidade aparente dos nutrientes em eqüinos.1999. 151p. Tese (Doutorado em Zooetcnia) - Universidade Federal de Lavras , Lavras, 1999.

ARAÚJO, K. V.; LIMA, J. A. F.; FIALHO, E. T. et al. Avaliação de períodos de coleta total de fezes para determinar a digestibilidade aparente dos nutrientes em eqüinos. Ciências agrotécnicas, Lavras, v.27, n.4, p.886-893, 2003.

ARAUJO, K. V.; LIMA, J. A. F., FIALHO, E. T. et al. Comparação entre os indicadores internos e o método de coleta total na determinação da digestibilidade dos nutrientes de alimentos volumosos em eqüinos. Revista Brasileira de Zootecnia, v.29, n.3, p.745-751, 2000.

BRITO, R.M.; SAMPAIO, A.A.M.; RESENDE, K.T. et al. Avaliação de indicadores para estimativa das digestibilidades parciais e total de dietas em bovinos. Revista Brasileira de Zootecnia, v.36, n.2, p.445-451, 2007.

$\mathrm{CHURCH}$, D.C. The ruminant animal digestive physiology and nutrition. Englewood Cliffs: O \& Books Inc. 1988, 564p.

COCHRAN, R. C.; VANZANT, E. S.; DELCURTO, T. Evaluation of internal markers isolated by alkaline hydrogen peroxide incubation and acid detergent lignin extraction. Journal of Animal Science, v.66, p.3245-3251, 1988.

COELHO DA SILVA, J. F.; LEÃO, M. I. Fundamentos de nutrição dos ruminantes. Piracicaba: Livroceres Ltda, 1979, 380p. 
CORREA, R. A.; SILVA, L. D. F.; BETT, V. et al. Consumo e digestibilidade aparente de alguns componentes nutritivos da silagem de sorgo (Sorgum bicolor L. Moench) com ou sem aditivos, em ovinos. Ciências Agrárias, Londrina, v.28, p.151-158, 2007.

CUDDERFORD, D.; HUGUIES, D. A comparison between chromium-mordant hay and acid insoluble ash to determine apparent digestibility of a chaffed, molassed hay/straw mixture. Equine Veterinary Journal, v.22, n.2, p.122-125, 1990.

CUDDERFORD, D.; PEARSON, R.A ; ARCHIBALD, R.F. Digestibility and gastrointestinal transit time of diets containining different proportions of alfafa and oats givem to Thoroughbreds, Sheteland ponies, Highland ponies and donkeys. Animal Science, v.61, p.407-417, 1995.

DETMANN, E.; PAULINO, M. F.; ZERVOUDAKIS, J. T. et al. Cromo e indicadores internos na determinação do consume de novilhos mestiços, suplementados, a pasto. Revista Brasileira de Zootecnia, v.30,n.5, p. 1600-1609, 2001.

FAHEY, G.C., JUNG, H.G. Lignin as a marker in digestion studies: a review. Journal of Animal Science, v.57, n.1, p.220-225, 1983.

FERRET, A.; PLAIXATS, J.; CAJA, G. et al. Using markers to estimate apparent dry matter digestibility, faecal output and dry matter intake in dairy ewes fed Italian ryegrass hay or alfafa hay. Small Ruminant Research, v.33, p. 145-152, 1999.

FONNESBECK, P. V.; SYMONS, L. D. Effect of a diet on concentration of protein, urea nitrogen, sugar and cholesterol of blood plasma of horses. Journal of Animal Science, v.28, p. 216-219, 1969.

FRAPE, D. L. Equine nutrition and feeding. Harlow: Longman Scientific Technical, 1992, $373 \mathrm{p}$.

FREITAS, D.; BERCHIELLI, T. T.; SILVEIRA, R. N. et al. Produção fecal e fluxo duodenal de matéria seca e matéria orgânica estimados por meio de indicadores. Revista Brasileira de Zootecnia, v.31, n.3, 2002.

FUKUSHIMA, R. S.; HATFIELD R. D. Composição fenólica de ligninas dioxano determinadas pela reação oxidativa com o nitrobenzeno. Pesquisa Agropecuária Brasileira, Brasília, v38, n.3, p.373-378, 2003. 
FUKUSHIMA, R. S.; DEHORITY, B. A.; LOERCH, S. C. Modification of a calorimetric analysis for lignin and its use in studying the inhibitory effect of lignin on forage digestion by rumen microorganisms. Journal of Animal Science, v.69, p.295, 1991.

FULLER, M.F. In vitro digestion for pigs and poultry. Wallingford: Redwood Press, 1991, 209p.

GOBESSO, A. A. O. Digestão pré-cecal e total de nutrientes utilizando diferentes dietas para eqüinos. 2001. 89p. Tese (Doutorado em Zootecnia) - Faculdade de Ciências Agrárias e Veterinárias, Jboticabal, 2001.

HEREDIA, A. Biophysical and biochemical characteristics of cutin, a plant barrier biopolymer. Biochimica et Biophysica Acta, v.1620, p.1-7, 2003.

HINTZ, H. F.; HINTZ, R. L.;VANVLEC, D. Growth rate of throughbreds. Effect of age of dam, year, month of birth, and sex of foal. Journal of Animal Science, v.48, n.3, p.408-417, 1979.

JANSSENS, G. P. J. Equine digestion. Proceedings of the First European Equine Nutrition \& Health Congress - Antwerp Zoo, Belgium, Feb. 9, 2002.

JUDKINS, M. B.; KRYSL, L. J.; BARTON, R. K. Estimating diet digestibility: a comparison of 11 techniques across six different diets fed to rams. Journal of Animal Science, v.68, p.1405-1415, 1990.

JUNG, H. G.; VOGEL, K. P. Influence of lignin on digestibility of forage cell wall material. Journal of Animal Science, v.62, p. 1703, 1986.

JUNG, H. G., BUXTON, D.; HATFIELD, R. et al. Improving forage fiber digestibility. Feed Mix, v.4, n.30, p. , 1996.

KNAPKA, J.J.; BARTH, K.M.; BROWN D.G. et al. Evaluation of polyethylene, chromic oxide, and cerium-144 as digestibility indicators in burros. The Journal of Nutrition, Philadelphia, v.92, n.1, p.79-85, 1967.

KOHN, R. A.; KALSCHEUR, K. F.; HANIGAN, M. Evaluation of models for balancing the protein requirements of dairy cows. Journal of Dairy Science, v.81, n.12, p.3401-3414, 1998. 
KOHNKE, J. R. Feeding and Nutrition. The making of a Champion. Birubi Pacific Copyright. Rouse Hill, p. 197, 1992.

KRYSL, L. J., GALYEAN, M. L., ESTELL, R. E. et al. Estimating digestibility and faecal output in lambs using internal and external markers. J. Agric. Sci., v.111, p.19-25, 1988.

LIPPKE, H.; ELLIS, W.C.; JACOBS, B.F. Recovery of indigestible fiber from feces of sheep and cattle on forage diets. Journal of Dairy Science, v.69, n.2, p.403-412, 1986.

LLOYD, L.E. Fundamentos de Nutricion. Zaragoza: Editorial Acribia,1978.464p.

MACHADO, H. M. Efeito de diferentes combinações de capim elefante (Penissetum purpureum Schum): cana de açúcar (Saccharum officinarum L.) sobre a digestibilidade, em eqüinos, utilizando diferentes metodologias. Dissertação de Mestrado - Universidade Federal de Viçosa, 71p., 1992.

MARTIN-ROSSET, W.; DOREU, M.; BOULOT, S. et al. Influence of level of feeding and physiological state on diet digestibility in light and heavy breed. Livestock Production Science. Amsterdam, v.25, p.257-264, 1990.

MAURICIO R.M. Determinação da digestibilidade aparente em eqüídeos através do oxido crômico, da lignina e da coleta total de fezes. Belo Horizonte: UFMG-EV, 1993, 62p. (Dissertação de mestrado em Zootecnia).

MAURICIO, R. M.; GONCALVES, L. C.; RESENDE, A. C. et al. Determinação da digestibilidade aparente em eqüídeos através do óxido crômico, da lignina e da coleta total de fezes. Arquivo Brasileiro Medicina Veterinária e Zooetcnia, v.48, n.6, p.703-11, 1996.

MAYNARD, L. A.; LOOSLI, J. K.; HINTZ, H. F. et al. Animal Nutrition. 7 ed. New York: Mc Graw-Hill, p.44-46, 1979.

MEYER, H. Alimentação de Cavalos.São Paulo: Livraria Varela Ltda. 303p.,1995.

MEYER, P. M. Fatores não nutricionais que afetam as concentrações de nitrogênio uréico no leite. Piracicaba: Escola Superior de Agricultura Luiz de Queiroz, Universidade de São Paulo, 2003, 131p. (Tese de Doutorado em Agronomia) 
MIRAGLIA, N.; BERGERO, D.; BASSANO, B. Et al. Studies of apparent digestibility in horses and use of internal markers. Livestock Prodution Science, v.60, p.21-25, 1999.

MOWAT, D. N.; KWAIN, M. L.; WINCH, J. E. Lignification and in vitro cell wall digestibility of plant parts. Can. J. Plant Sci., v.49, p. 499-504, 1969.

MUNTIFERING, R.B. Evaluating of various lignin assays for determing ruminl digestion of roughages by lambs. Journal of Animal Science, 55 (2): 432-438,1982.

NYBERG, M.A. Flow rate through the small intestine of the equine determined with soluble and insoluble indicators given in a pulse and steady -state dose. (Thesis Master of Science in animal Science). Texas A\&M University, 70p. 1993.

OLIVEIRA, A. A. M. A. Digestão total e pré-cecal dos nutrientes em potros fistulados no íleo. Viçosa: UFV, 1995. 92p. Dissertação (Mestrado em Nutrição de Monogástricos) - Universidade Federal de Viçosa, 1995.

OLIVEIRA, C. A. A.; ALMEIDA, F. Q.; VALADARES FILHO, S. C. et al. Estimativa da digestibilidade aparente de nutrientes em dietas para eqüinos, com o uso de óxido crômico e indicadores internos. R. Bras. Zootec., v.32, n.6, p.1681-1689, 2003 (Supl. 1).

OLIVEIRA JUNIOR, R.C.; PIRES, A.V.; RESENDE, J.J. et al. Avaliação de indicadores para estimar a digestibilidade dos nutrientes em novilhos Nelore alimentados com dietas contendo alto teor de concentrado e fontes nitrogenadas. Rev. Bras. Zootec., v.33, n.3, p.749-758, 2004.

OLSSON, N.; RUUDVERE, A. The nutrition of the horse. Nutrition Abstracts and Reviews, London, v.25, n.1, p.1-18, jan.1955.

PAGAN, J. Forages for horses: More than just a filler. In Advances in Equine Nutrition, pp. 13-27 [J Pagan, editor]. Nottingham, UK: Nottingham University Press,1998.

PARKINS, J. J.; SNNOWD, H.; ADAMS, S. The apparent digestion of "complete diets" cubes given to throughbred horses and the use of chromic oxide as an internal fecal marker. Bristh Vet Journal. v.138, p.350-355, 1982. 
PEREIRA, J. C.; QUEIROZ, A. C. Digestibilidade aparente em eqüinos alimentados com capim elefante (Pennisetum purpureum Schum) e cana-de-açúcar (Saccharum officinarum L.) em diversas combinações. Rev. Bras. Zootec., v.26, n.1, p.105-110, 1997.

PEREIRA, J. C.; QUEIROZ, A. C., CARMO, M. B. Avaliação de métodos para determinação da digestibilidade aparente em equinos. Revista da Sociedade Brasileira de Zootecnia, v.24, n.3, p.382-390, 1995.

SAS, 1998. SAS/STAT User's Guide, Release 7.0 ed. SAS Institute, Cary, NC. SCHNEIDER, B.H., FLATT, W.P. The evaluation of feeds through digestibility experiments. The University of Georgia Press. Athens, Georgia, 423p., 1975.

SILVA, D.J. Análise de alimentos (métodos químicos e biológicos). Viçosa: UFV, 1665 p., 1990.

SILVA, J.F.C.; CAMPOS, J.; CONRAD J.H. Uso do oxido crômico na determinação da digestibilidade. Experientiae, v8, p.1-23, 1968.

SILVA, L. D. F.; EZEQUIEL, J. M. B.; AZEVEDO, P. S. et al. Uso da cutina na estimativa das digestões total e parcial de alguns componentes de rações contendo diferentes fontes de nitrogênio, em bovinos. R. Bras. Zootec., v.35, n.2, p. 600-606, 2006.

SANKHYAN, S.K.; SHINDE, A.K.; BHATTA, R. et al. Comparison of diet and faecal collection methods for assessment of seasonal variation in dry matter intake by sheep maintained on a Cenchrus ciliaris pasture. Animal feed Science and Technology, v82, p.261-269, 1999.

STEIN, R. B. S.; TOLEDO, L. R. A.; ALMEIDA, F. Q. et al. Estimativa da digestibilidade aparente da matéria seca por meio de indicadores internos em eqüinos. R. Bras. Zootec., v.35, n.2, p. 504-511, 2006.

STILLIONS, M.C.; NELSON, N.E. Metabolism stall for male equine Journal Animal Science. v.27, n.1, p.68-72, 1968.

SUNVOLD, G. D.; COCHRAN, R. C. Technical note: evaluation os acid detergent lignin, alkaline peroxide lignin, acid insoluble ash and indigestible acid detergent alfafa, bromegrass and prairie hay digestibility by beef steers. Journal of Animal Science, v.69, p.4951-4955, 1991. 
TAMMINGA, S.; ROBINSON, P. H.; MEJILS, S. et al. Feed components as internal markers in digestion studies with dairy cows. Anim. Feed Sci. Technol., v 27, p.4957, 1989.

TODD, K. L.; SAUER, W. C. ;CHRISTOPHERSON, R. J. et al. The effect of level of feed intake on nutrient and energy digestibility and rate of feed passage in horses. Journal Animal Physiology and Animal Nutrition, v.73, p.140-148, 1995.

UDEN, P.; COLUCCI, P.E.; VAN SOEST P.J. Investigation of chromium, cerum and cobalt as markers in digesta. Rate of passage studies. Journal Sci.Agric.31: 625632, 1980.

VAN DER NOOT, G.W.; FONNESBECK, P.V.; LYDMAN, R.K. ; Equine Metabolism stall and collection harness. Journal of Animal Science. Champaign, v.24, n.3, p.691-698.1965.

VAN SOEST, P.J.; ROBERTSON, J.B.; LEWIS, B.A. Methods for dietary fiber, neutral detergent fiber and nonstarch polysaccharides in relation to animal nutrition. Journal of Dairy Science, Champaign, v.74, p.2066-2074, 1991.

VAN SOEST, P. J. Cell wall matrix interactions and degradation - Session synopsis. In: H. G. Jung, D. R. Buxton, R. D. Hatfield,and J. Ralph (Ed.) Forage Cell Wall Structure and Digestibility, p 377. ASA-CSSA-SSSA, Madison, WI., 1993.

VAN SOEST, P.J. Nutritional ecology of the ruminant. Ithaca: Comstock Publishing Associates/ Cornell University Press, p.476, 1994.

VASCONCELLOS, C.H.F. Lignina purificada e modificada (LIPE®), óxido crômico e coleta total de excretas, como métodos de determinação da digestibilidade em frangos de corte. 2004. 46 p. (Dissertação de Mestrado em Zootecnia) Universidade Federal de Minas Gerais, Belo Horizonte.

VASCONCELLOS, R. S.; CARCIOFFI, A. C.; OLIVEIRA, L. D. et al. Utilização de indicadores para estimar a digestibilidade aparente em gatos. Arq. Bras. Med. Vet. Zootec., v.59, n.2, p.466-472, 2007.

ZEYNER, A.; KIENZLE, E. A method to estimate digestible energy in horse feed. Journal of Nutrition, v.132, p. 1771-1773, 2002. 
WOLTER, R. Alimentação del Caballo. Zaragosa: Acribia, 172p., 1975. 